DIW BERLIN

Discussion Papers

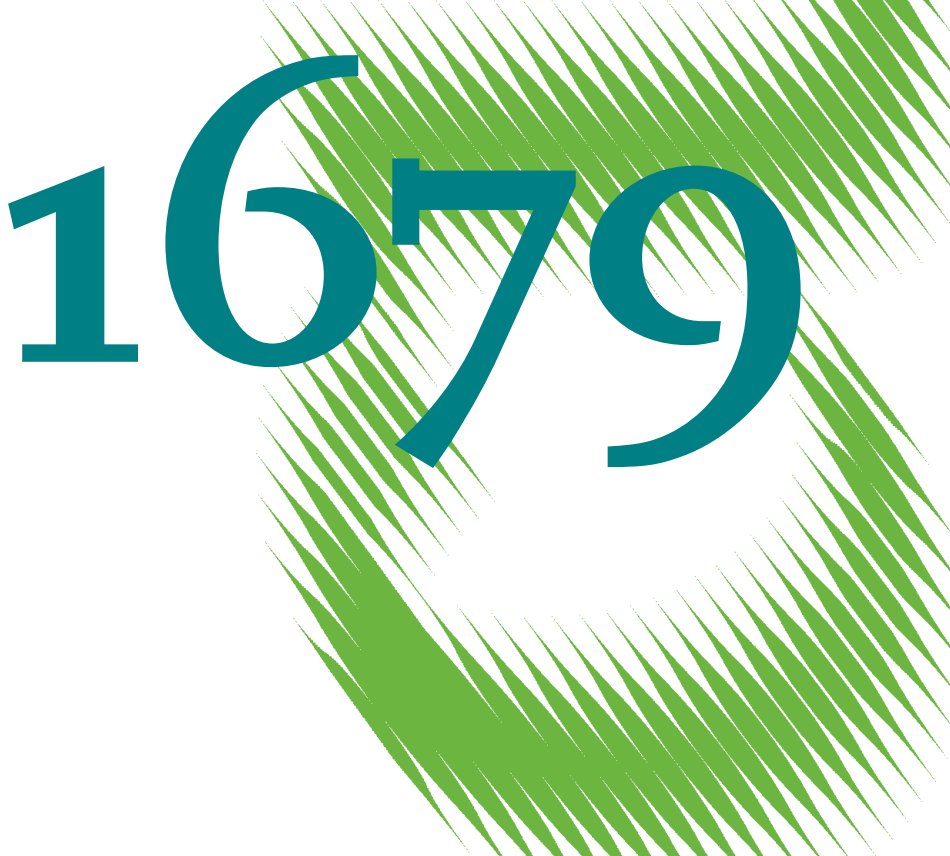

The Effect of Partial Retirement on Labor Supply, Public Balances and the Income Distribution

Evidence from a Structural Analysis 
Opinions expressed in this paper are those of the author(s) and do not necessarily reflect views of the institute.

IMPRESSUM

(C) DIW Berlin, 2017

DIW Berlin

German Institute for Economic Research

Mohrenstr. 58

10117 Berlin

Tel. +49 (30) $89789-0$

Fax +49 (30) $89789-200$

http://www.diw.de

ISSN electronic edition 1619-4535

Papers can be downloaded free of charge from the DIW Berlin website:

http://www.diw.de/discussionpapers

Discussion Papers of DIW Berlin are indexed in RePEc and SSRN:

http://ideas.repec.org/s/diw/diwwpp.html

http://www.ssrn.com/link/DIW-Berlin-German-Inst-Econ-Res.html 


\title{
The Effect of Partial Retirement on Labor Supply, Public Balances and the Income Distribution -Evidence from a Structural Analysis*
}

\author{
Songül Tolan ${ }^{\dagger}$ \\ Deutsches Institut für Wirtschaftsforschung, Berlin \\ Free University of Berlin
}

August 2017

\begin{abstract}
This paper develops a structural dynamic retirement model to investigate effects and corresponding underlying mechanisms of a partial retirement program on labor supply, fiscal balances, and the pension income distribution. The structural approach allows for disentangling the two counteracting mechanisms that drive the employment effects of partial retirement: 1) the crowding-out from full-time employment, and 2) the movement from early retirement or unemployment to partial retirement. It also allows for investigating the role of financial compensations in a partial retirement program. Based on a unique German administrative dataset, I perform counterfactual policy simulations that analyze the role of partial retirement combined with financial subsidies and an increased normal retirement age. The results show that partial retirement extends working lives but reduces the overall employment volume. The fiscal consequences of partial retirement are negative but substantially less so when wages and pensions in partial retirement remain uncompensated. Partial retirement decreases inequality in pension income and provides a way to smooth consumption especially for retirees in lower income deciles in the context of an increased normal retirement age.
\end{abstract}

JEL: C61, J26, H55

Keywords: Retirement, Partial Retirement, Social Security and Public Pensions, Structural estimation, Dynamic Discrete Choice

\footnotetext{
*Valuable comments by Peter Haan, Arthur van Soest, Johannes Geyer, Tunga Kantarci and participants at the Netspar International Pension Workshop 2017 as well as seminars at the DIW and the CPB in The Hague are gratefully acknowledged. I thank the Forschungsnetzwerk Alterssicherung (FNA) for financial support through a Ph.D. scholarship. In addition, I thank Netspar for financial support through the Medium Vision Grant (Project name: Flexible combinations of work and retirement).

${ }_{\dagger}^{\dagger}$ stolan@diw.de
} 



\section{Introduction}

Population aging is increasing the financial burden on pay-as-you go funded public pension systems in many countries. The sustainability of such pension systems is challenged as the group of elderly recipients increases while the group of those contributing to the system decreases. A promising way to counteract this imbalance is to increase the labor force participation of the elderly by extending working lives (Maestas and Zissimopoulos, 2010). Consequently, increasing attention is being paid to measures that motivate elderly employees to remain in the workforce longer in order to extend their time on the contributing side of the social security equation.

Most recently, many European countries introduced partial retirement programs into their pension systems and, in the face of population aging, practically every partial retirement program aims to motivate elderly employees to stay longer in employment (Eurofound, 2016). The idea behind increasing labor supply through partial retirement is that a gradual phasing out of work instead of abrupt full retirement encourages workers to stay longer in employment. However, the employment effects of partial retirement programs are ambiguous. Partial retirement may increase labor supply if people opt for partial retirement instead of full early retirement but substituting full-time employment with partial retirement would also require individuals to spend more years in employment in order to actually increase their overall labor supply. That is, partial retirement might also generate negative employment effects if it crowds out years that would have been spent in full-time employment. The direction of the employment effect also depends on the design of the partial retirement scheme and evidence on underlying mechanisms that drive the effects of partial retirement is still scarce. Since there is no clear definition of the term "partial retirement" in the literature (Bloemen et al., 2016), this study defines it as a reduction in work hours in the last job held prior to entering retirement.

In this paper I develop a structural dynamic retirement model to investigate the effects of partial retirement on employment and retirement behavior, fiscal balances as well as the pension income distribution. The biggest challenge to the empirical literature that measures the effects of partial retirement is that it cannot be observed what partial retirees would have done had it not been possible to enter the partial retirement path. Instead of exploiting an exogenous variation to the retirement decision (e.g. through a reform) this study approaches the identification problem by explicitly modeling the drivers (financial and non-financial) of individual retirement decisions. The basic model consists of an individual's annual choice to continue working or exit employment through one of three possible retirement paths: 1) regular retirement, 2) retirement via bridge unemployment, or 3) retirement via partial retirement. The choice is subject to employment and mortality risks. In addition, access to partial retirement is restricted. Finally, the model incorporates a tax and transfer system as well as the rules of the underlying pension system. Besides controlling for the endogeneity of the retirement decision as well as the dynamic nature of the problem, the structural approach further enables the modeling of idiosyncratic aspects of the scheme, such as financial subsidies, and counterfactual policy simulations. In addition, this revealed preference approach allows identifying partial retirement preferences directly at the relevant decision margin. 
Based on the estimation of structural parameters of individual employment behavior, I perform policy simulations that investigate different aspects of a partial retirement policy. First, in order to understand the effect of just introducing partial retirement in the present system, I simulate unrestricted access to partial retirement. Secondly, since the role of partial retirement as an option to extend working lives through a lower immediate amount of work may be increasing in the face of increasing retirement ages (Eurofound, 2016), I investigate the effect of partial retirement in the context of an increase of the normal retirement age (NRA) from 65 to 67 . Finally, I investigate the role of compensating wage and pension accrual subsidies for partial retirees.

I make use of a unique administrative dataset, the Biographical Data of Social Insurance Agencies in Germany (BASiD), which combines information on employment history, wages, and partial retirement take-up with the information on corresponding public pension accrual. The combination of the date of partial retirement take-up with pension point accrual is unique since this information is collected by two different government agencies and essential to the present research question as this study not only looks at the ad-hoc effects of retirement decisions but also considers a trade-off between current and future income streams of forward-looking individuals. In addition, compared to survey data, this dataset contains personal information, e.g. on wages or education, that does not suffer from non-response or reporting bias. The focus of this study lies on West German men, which constitutes the largest group of workers in partial retirement.

Determining the sign of the labor supply effect of partial retirement is difficult because the additional retirement path competes with the take-up of alternative employment states that would yield higher (e.g. full-time employment) or lower (e.g. unemployment or early retirement) labor supply. Which of these counteracting substitutions dominates the other depends on the way partial retirement is used. It may yield a positive effect, e.g. if employers use partial retirement to maintain their human capital by keeping experienced employees longer in their firms in order to teach newly hired workers (see e.g. Ghent et al., 2001; Munzenmaier and Paciero, 2002). It can also yield negative effects if partial retirement is used as a tool to renew the working force in firms by reducing work hours of elderly employees and practically sending them off to retirement earlier. For employees partial retirement may be seen as a way to remain in the labor force longer and keep social relations at work even if full-time employment is not wanted or not possible due to health reasons. In addition, staying employed longer, even in part-time, could curtail cognitive decline in higher ages (Rohwedder and Willis, 2010; Bonsang et al., 2012), which could motivate employees to extend their working lives in partial retirement. However, if partial retirement only signals preferences for early retirement (Machado and Portela, 2012) the employment effects may be negative. Financial incentives for partial retirement could also limit positive labor supply effects if it increases its attractiveness relative to full-time employment (Börsch-Supan et al., 2015).

Empirical findings on the effect of partial retirement on labor supply are sparse and ambiguous. For instance, Ghent et al. (2001) and Albanese et al. (2016) find nega- 
tive employment effects from partial retirement programs at the University of North Carolina and in Belgium, respectively, whereas Wadensjö (2006) finds exactly the opposite for a Swedish partial retirement program. Graf et al. (2011) analyze the Austrian old age part-time scheme that is institutionally very similar to the German partial retirement policy 'Altersteilzeit' (ATZ) and find a cumulative negative effect on employment over the five year duration of the program. The effects of the German ATZ policy are studied by Berg et al. (2015) and Huber et al. (2016). Both studies distinguish between labor market exit and retirement entry since factual retirement can start earlier in Germany if individuals bridge the transition to retirement with unemployment insurance take-up. While Berg et al. (2015) find an overall positive effect of ATZ on the average labor market exit age, the results by Huber et al. (2016) are more modest. Moreover, Huber et al. (2016) only find a significant positive effect for East Germany and no effect for West Germany, which they attribute to differences in labor market conditions between the regions. Stated-preference approaches identify partial retirement preferences by individual ranking of hypothetical retirement schemes (Van Soest et al., 2007; Elsayed et al., 2015) and find that elderly workers can be motivated to work beyond the NRA in part-time if compensated adequately.

This paper is in line with the literature that uses structural research approaches to model retirement behavior (e.g. Rust, 1989; Stock and Wise, 1990; Rust and Phelan, 1997; Benitez-Silva, 2000; Heyma, 2004; Karlstrom et al., 2004; French, 2005; Blau, 2008; Van der Klaauw and Wolpin, 2008). Although some of these studies implement part-time labor, all of them model retirement as a binary decision. Gustman and Steinmeier (2008) present a noteworthy difference. They analyze the effect of partial retirement on the employment behavior of married men in the context of a dynamic structural retirement model using data form the US Health and Retirement Study. They find that removing restrictions for partial retirement generates an overall positive effect of partial retirement on total labor supply.

Finally, given the simulated policies this paper contributes to the literature on alternative paths into retirement (e.g. Staubli, 2011; Inderbitzin et al., 2016) and to studies that analyze the effect of an increase in early retirement age (ERA) or NRA on actual retirement age (e.g. Duggan et al., 2007; Li and Maestas, 2008; Staubli and Zweimüller, 2013; Atalay and Barrett, 2015; Geyer and Welteke, 2017). The increase of the NRA from 65 to 67 is still in a transitional process in Germany and was only studied in a structural context with an ex-ante analysis by Etgeton (2017).

The analysis yields the following results. Introducing the option to retire via partial retirement extends working lives by about four to five months by reducing the number of individuals exiting employment early via unemployment. However, overall employment volume still decreases by on average $4.71 \%$ if the NRA is at 65 and by on average $3.86 \%$ if the NRA is at 67 due to a large share of individuals that substitute full-time employment with partial retirement. With a reduction in employment volume by about $10 \%$ this effect is stronger when wages and pensions are subsidized in partial retirement. Subsidizing partial retirement also leads to a reduction in net balances by an additional 9,500 to 13,500€ per person. More importantly, I find that income inequality in pensions is reduced with the introduction of partial retirement. However, not compensating pension accumulation in partial retirement leads to a 
decrease in pensions across almost all income deciles but these reductions are less pronounced when the NRA is 67 since more people bridge the time between ERA and NRA with partial retirement. Especially for lower income deciles partial retirement provides a way to smooth consumption when transitioning into retirement in the context of an increased NRA.

The rest of this paper is structured as follows. Section 2 introduces the dynamic decision model and the estimation strategy, section 3 presents the data and descriptive analysis, section 4 presents the estimation results, section 5 discusses counterfactual policy simulations, and section 6 concludes.

\section{Model}

This section introduces a dynamic structural life-cycle model of individuals' retirement decisions at pensionable age. The institutional background is incorporated in this model as closely as necessary. ${ }^{1}$ The core of this model is based on the standard dynamic retirement model by Rust (1989). A forward-looking individual $i$ derives utility at time $t$ from consumption $\left(C_{i t}\right)$ and has leisure preferences that vary over employment states $\Gamma_{i t}^{k}$. $\mathrm{He}^{2}$ maximizes his expected remaining lifetime utility through annual decisions between continuing to work or employment exit via regular retirement, retirement via bridge unemployment, or partial retirement. The individual's horizon ranges from age 55 to $T=100$ but decisions can only be made from age 55 to age 65 , where everyone is in retirement at age 65 . Moreover, there are two sources of uncertainty: job loss and mortality.

Figure 1 illustrates the structure of the decision problem. The model is conditioned on being employed at age $54 .^{3}$

Every period, the individual faces the risk of job loss with probability $\Phi_{i t}^{u}$. Individuals that lose their jobs cannot return to the labor market. This assumption is supported by the data as only a very small fractions returns to the labor market after unemployment in the observed age range. The expected value of job loss is divided into three different phases: before age 58, between 58 and 62, and between 63 and 65 . Individuals that loose their job before age 58 receive at least one year of unemployment insurance, then social assistance until they enter regular retirement. ${ }^{4}$ Individuals that lose their job at age 58 -with at least two years of unemployment insurance eligibility- will enter retirement after at least two years of unemployment insurance receipt. ${ }^{5}$ If job loss occurs after age 63 , the individual can either decide

\footnotetext{
${ }^{1}$ The institutional background is described in a bit more detail in Appendix A

${ }^{2}$ I use the male form for the decision maker because the present study focuses on retirement decisions of West German men.

${ }^{3}$ This assumption introduces favorable selection in terms of labor market history and income. However, it also conditions on the eligibility criteria for partial retirement. The decisions of individuals not eligible for partial retirement yield no information on the preferences for partial retirement.

${ }^{4}$ I include this group in the model due to their eligibility for partial retirement prior to job loss.

${ }^{5}$ I assume that individuals use the full duration of their unemployment insurance eligibility. Due to sample restrictions discussed in Section 3, every individual is eligible to at least one year of
} 
Figure 1: Structure of the decision problem

unemployment

before 58

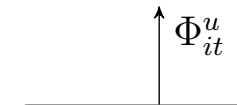

annual decision

work or exit

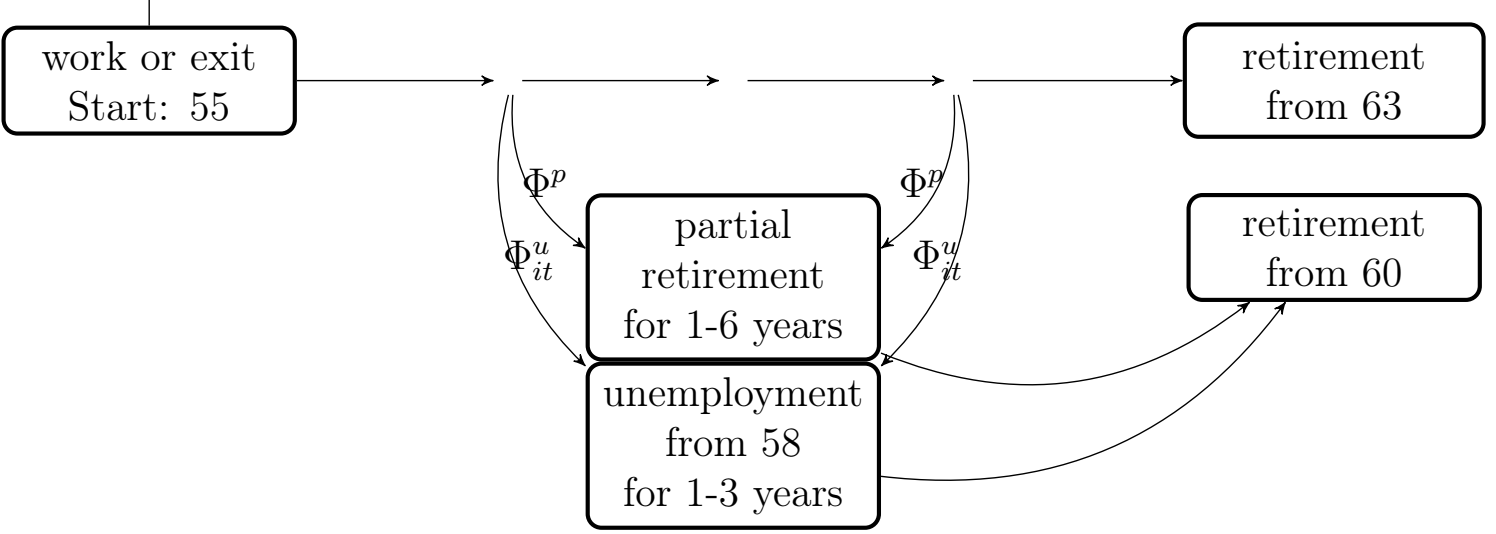

Own illustration

between immediate regular old-age pension or retirement after unemployment.

If job loss does not occur, with probability $\Phi_{i}^{p}$ the individual can decide between the following options:

1. continue to work in full-time $(f)$

2. exit work through 1 to 6 years of partial retirement and eventual full retirement $\left(p_{a}\right)$, where $a \in\{1, \cdots, 6\}^{6}$

3. exit work through bridge unemployment insurance or social assistance and eventual retirement $(r u)$

4. from age 63: exit work either through regular old-age retirement (re) or the other two retirement paths

However, due to the fact that partial retirement is not a legal right but based on an employer-employee agreement, there is a probability $\left(1-\Phi_{i}^{p}\right)$ that the individual has no access to partial retirement. This produces two potential choice sets sets $D^{p}=\left\{f, p_{a}, r u, r e\right\}$ and $D^{n p}=\{f, r u, r e\}$. To continue working is the only option with a continuation value. All other options are exit paths into retirement. Thus, the basic structure is a classic optimal stopping problem but with three instead of one exit option.

Assuming additive separability of utility over time, the decision problem can be written as

unemployment insurance.

${ }^{6}$ Note that opting for partial retirement has the additional value of job security. This is due to the fact that take-up and duration of partial retirement is predefined in an employer-employee arrangement. Thus, partial retirement take-up inherits the additional decision over the duration in partial retirement. 


$$
\max _{d_{i t}} E_{t_{0}}\left[\sum_{t=t_{0}}^{\tilde{t}} \pi_{t} \delta^{t-t_{0}} U\left(C_{i t}, \Gamma_{i t}^{k} \mid d_{i t}\right)+\sum_{t=\tilde{t}+1}^{T} \pi_{t} \delta^{t-t_{0}} U\left(C_{i t}, \Gamma_{i t}^{k} \mid d_{i \tilde{t}}\right)\right]
$$

where $\pi_{t}^{7}$ denotes the probability of living until age $t$ conditioned on being alive at age $t-1, \delta$ denotes the discount factor and the maximum attainable age is denoted $T$ which is set to 100 .

In the individual's decision horizon, we distinguish between two phases: the decision phase (the first term of Equation 1) and the retirement phase (the second term of Equation 1). The decision phase ranges from $t=55$ until $\tilde{t}$, where $\tilde{t}$ is either age 65 or the age at which one of the exit options was chosen. After $\tilde{t}$ utility evolves deterministically and choices can no longer be made.

The individual controls his consumption $\left(C_{i t}\right)$ and employment-state-specific utility $\left(\Gamma_{i t}^{k}\right)$ through decisions that affect his employment status $(k)$, where $k$ can either be full time employment $(f)$, partial retirement $(p)$, unemployment $(u)$ or full retirement $(r)$. In this study consumption equals income $\left(C_{i t}=y_{i, t}^{k}\right)$ which is explained in more detail in Section 2.4 .

In the following chapters I subsequently describe (i) the utility function (ii) partial retirement (iii) pension accumulation (iv) the budget constraint (v) the tax and transfer system (vi) job loss probabilities and finally combine these components in the dynamic programming framework.

\subsection{Utility function}

With regard to consumption, all individuals exhibit constant relative risk aversion $(C R R A)$ in their within-period utility flows. Furthermore, individuals have preferences for each employment state $k$. The within-period utility function for individual $i$ at period $t$ in employment state $k$ can be written as

$$
U_{i t}^{k}=\frac{\left(C_{i t}^{k}\right)^{(1-\rho)}-1}{1-\rho}+\Gamma_{i t}^{k}+\epsilon_{i t}\left(d_{i t}\right)
$$

where $\rho$ denotes the coefficient of relative risk aversion and $\epsilon_{i t}$ is a choice-specific random shock which follows a type-one extreme value distribution. $C_{i t}^{k}$ denotes consumption of individual $i$ in period $t$ in employment state $k$ and is elaborated in detail in Section 2.4. Similar to Heyma (2004), individuals exhibit leisure preferences relative to their employment state $k, \Gamma_{i t}^{k}$ which is defined as follows.

$$
\Gamma_{i t}= \begin{cases}0 & \text { if } k=f \\ \lambda_{0}+\lambda_{1} \cdot\left(\text { age }_{i t}-59\right) & \text { if } k=r \\ \theta_{0}+\theta_{1} \cdot \mathbf{1}\left[\text { age }_{i t}>=60\right] & \text { if } k=p \\ v_{0}+v_{1} \cdot \mathbf{1}\left[\text { age }_{i t}>=60\right] & \text { if } k=u\end{cases}
$$

Thus, the baseline employment state is full-time employment and individuals experience the additional leisure time in the other employment states differently. Note that

\footnotetext{
${ }^{7}$ Survival probabilities are obtained from the mortality database of the German Statistical Office and conditioned on gender and cohort (Statistisches Bundesamt).
} 
individuals can only enter retirement at the earliest from the age of 60 . Therefore, preferences for leisure in retirement $\left(\lambda_{0}+\lambda_{1} \cdot\left(a g e_{i t}-59\right)\right)$ can only be realized from the age of 60 . Moreover, I include an age trend for retirement preferences $\left(\lambda_{1}\right)$ which is expected to be positive in order to account for increasing leisure preferences as people age, e.g. due to deteriorating health (see e.g. Gustman and Steinmeier, 2005). In addition, $\theta$ and $v$ represent the experience of time spent in partial retirement and unemployment, respectively. Note that I let these differ for the periods before and after the earliest possible retirement age (60). The individual's choice set changes as the option for full retirement becomes available at age 60. Therefore, preferences for each employment state are allowed to differ between these two choice sets. The rationale behind this is as follows. Individuals have increasing utility for leisure. Before retirement entry is possible, $v_{0}$ mainly represents preferences for leisure, since this is the only option for full leisure prior to retirement. However, it can be expected that unemployment insurance receipt is accompanied by a stigmatizing effect which yields disutility (Moffitt, 1983). At the same time, partial retirement is the only option to decrease labor without a stigmatizing effect. Full retirement opens up an additional option to increase leisure without social stigma. Thus, in both states partial retirement and unemployment, the non-financial preferences relative to full-time employment should be lower than the preference for full retirement; in unemployment due to the stigma effect, and in partial retirement due to the lower leisure level. The preferences for these employment states in relation to full retirement are only realized once full retirement is in the choice set.

\subsection{Partial retirement}

I identify preferences for partial retirement through take-up of part-time work for elderly employees (known in Germany as Altersteilzeit). ${ }^{8}$ Employees can take up partial retirement from the age of 55 by reducing their work hours prior to retirement by $50 \%$. Wage and pension accumulation losses during the partial retirement period are compensated either by the respective employers or the Federal Employment Agency where the law sets a minimum for both compensations. I model subsidies for partial retirement according to these settings. That is, wage compensations in partial retirement amount to $20 \%$ of equivalent full-time employment wages $\left(s u b^{w}=0.2\right)$ and pension accrual compensations amount to $40 \%\left(s u b^{r}=0.4\right)$.

Moreover, the model has to account for the fact that access to partial retirement is not a legally binding right but an agreement between employer and employees. Therefore, as mentioned above, with a probability $\left(1-\Phi^{p}\right)$, the individual's choice set does not contain the option to enter partial retirement. Whether or not an individual has access to partial retirement, cannot be observed in the data. Since the model is estimated by Maximum Likelihood, I construct a likelihood that is adjusted by $\Phi^{p}$ depending on actual partial retirement-take-up. I set $\Phi^{p}=35 \%$ which is based on information obtained from Wanger (2009). ${ }^{9}$

\footnotetext{
${ }^{8}$ Details on introduction, conditions and take-up of the policy are described in Appendix A.1

${ }^{9}$ In particular, Wanger (2009) states that $15 \%$ of employees in small firms, where $40 \%$ of the age-wise eligible for partial retirement work, take up partial retirement. The partial retirement takeup rate in the remaining firms is $36 \%$ to $44 \%$. Due to its financial incentives, partial retirement is taken up by most employees who have access to it.
} 


\subsection{Pension accumulation}

The German Statutory Pension Insurance, is a pay-as-you-go funded system. Contributions to the system are collected in a payroll tax throughout the working life in the form of annual pension points $\left(p p_{i t}\right)$ which are based on a ratio of the individual gross wage $\left(w_{i t}\right)$ to the annual specific average wage of all insured $\left(\bar{w}_{t}\right)$, i.e. $p p_{i t}=w_{i t} / \bar{w}_{t}$. Annual contributions are capped by a ceiling which varies at around two pension points.

The model incorporates the fact that the individual's pension points are changing throughout the decision process according to the respective employment state as follows

$$
P_{i t}= \begin{cases}P_{i t-1}+p p_{i t}\left(w_{i t}\right) & \text { if } k_{t}=f \\ P_{i t-1}+\left(\frac{1}{2}+s u b^{r}\right) \cdot p p_{i t}\left(w_{i t}\right) & \text { if } k_{t}=p \\ P_{i t-1}+0.8 \cdot p p_{i t}\left(w_{i t}\right) & \text { if } k_{t}=u\end{cases}
$$

Thus, regular pension points from full-time employment are adjusted in partial retirement or unemployment. Here, I follow the institutional settings closely and set $s u b^{r}=0.4$, which denotes the pension points replacements provided by the partial retirement program. Pension points during unemployment insurance receipt equal the pension points from full-time wages adjusted by 0.8 .

\subsection{Budget constraint}

In this model consumption equals net income, i.e. $C_{i t}^{k}=y_{i, t}^{k}$. This is in line with Rust and Phelan (1997) who mainly motivate this with problems of imputing missing wealth information. Despite the lack of a savings process the model still features decisions that affect intertemporal income. Given the underlying institutional settings, a pensioner's pension level is determined by his entire earnings and employment history. More specifically, an additional year of labor increases the individual's pension in the future. Furthermore, the system incorporates financial penalties and rewards on pension annuities for earlier or later retirement, respectively. The institutional background is described in more detail in Appendix A. In the following, I will elaborate on the income differences across employment states.

An individual's net-income at period $t$ in employment state $k\left(y_{i, t}^{k}\right)$ depends on his gross wages for his last observed state in full employment up to period $t^{10}$ and is subject to taxes as well as social security contributions. ${ }^{11}$

\footnotetext{
${ }^{10}$ The sample is conditioned on individuals in full-time employment at age 54. Therefore, I observe gross labor earnings from full-time employment in at least one period per individual.

${ }^{11}$ All monetary values in this analysis are price adjusted to 2005.
} 
Income in full-time employment The administrative dataset provides information about gross daily wages for working individuals. The net annual income for a working individual $\left(y_{i t}^{f}\right)$ equals gross annual labor market earnings minus social security contributions and income tax. Similar to Manoli et al. (2014), who estimate a structural retirement model using Austrian data, the data shows little intertemporal variation in wages for elderly working individuals. Therefore, I apply the same approach to modeling future earnings by assuming that earnings $w_{i t}^{f}$ increase linearly by a growth rate $g$, such that

$$
y_{i t+1}^{f}=G\left((1+g) w_{i t}^{f}\right)
$$

where $G($.$) denotes the model of the tax and transfer system and social security con-$ tributions which is explained in more detail in Section 2.5.

Income in partial retirement According to the institutional setting ${ }^{12}$, income in partial retirement includes a compensation of full-time employment wages of at least $20 \%$ which is paid as a wage subsidy $s u b^{w}=0.2$. Furthermore, the institutional background ensures that part-time wage penalties are not an issue. This yields the following specification for income in partial retirement.

$$
y_{i t}^{p}=G\left(\left(\frac{1}{2}+s u b^{w}\right) w_{i t}^{f}\right)
$$

The individual obtains partial retirement income for the number of years that he has chosen to remain in partial retirement. The time in partial retirement is automatically followed by retirement.

Income in unemployment On average, unemployment insurance amounts to $60 \%$ of the net-income that the individual received in the employment period prior to unemployment (Haan and Prowse, 2015). Thus, income in unemployment is specified as follows.

$$
y_{i t}^{u}=0.6 \cdot\left(G\left(w_{i t}^{f}\right)\right)
$$

Individuals receive unemployment insurance according to their entitlement between one and three years. I assume that the decision maker takes up the maximum of his entitlement at unemployment insurance receipt. After that, the individual either receives social assistance or his pension depending on the respective employment status.

Income in retirement An individual in retirement receives an annual pension in period $t\left(y_{i t}^{r}\right)$ that is fixed from the moment of retirement entry up to the final period $T$. At retirement entry in period $\tilde{t}$, annual pension income is calculated as follows.

$$
y_{i t}^{r}=12 \cdot P_{i \tilde{t}} \cdot Z(\text { ra, rp }, \text { cohort }) \cdot p v_{t}
$$

\footnotetext{
${ }^{12}$ See Appendix A.1 For details on the institutional setting of partial retirement.
} 
where $y_{i t}^{r}$ represents the annual pension income of individual $i$ at period $t, P_{i \tilde{t}}$ equals the individuals total sum of pension points collected up to period $\tilde{t}, Z$ represents the retirement access factor and $p v_{\tilde{t}}$ represents the institutional pension value in year $\tilde{t}$. $Z$ is equal to one if the individual opts for regular retirement at the NRA. Then, there are deductions of $3.6 \%$ for every year that the individual enters retirement below the normal retirement age. ${ }^{13}$ In addition, there is further variation in $Z$ through cohort-based reforms for different retirement paths $r p$ which are illustrated in Table 11 in Appendix B. This introduces a cohort-based exogenous variation in pension levels that supports the identification of structural parameters.

\subsection{Tax and transfer system}

Taxes as well as social security contributions (SSC) differ substantially across employment states. They therefore affect retirement decisions through their effect on income. To control for this, I include a model of the tax and transfer system that incorporates the key differences across employment states. The base year for these institutional settings is 2005. This includes the legislative settings for taxation in different employment states and price adjustments.

Due to lack of demographic information, I model taxes and transfers for a single earner household. The model considers a progressive income tax and differences in SSC across employment states. The wage compensations for partial retirees are not taxed but are still subject to the progression clause. This implicitly provides further financial incentives for partial retirement. Pensions are only taxed by $50 \%$ and exempt from pension contributions. Net income in unemployment insurance roughly equals $60 \%$ of previous net labor earnings. Furthermore, the model considers compensations in earnings and pension point accumulation for partial retirement and unemployment insurance receipt. Finally, all income is bounded from below by social assistance. Overall, this model incorporates the key differences in financial incentives across employment states.

\section{$2.6 \quad$ Job loss risk}

The individual's employment decision is subject to labor demand frictions. Similar to Haan and Prowse (2014) and Merkurieva (2016), the risk of involuntary job loss $\left(\Phi_{i t}^{u}\right)$ is estimated in a first stage random effects logit regression based on the German Socio-Economic Panel (SOEP) ${ }^{14}$. The dataset contains information on employment status and self-reported reasons for job termination. Job loss is defined as involuntary if the respondent has one of the following reasons for job termination: 1) Company shut down, 2) Dismissal, and 3) Temporary contract expired. I let the risk of job loss depend on personal characteristics that are contained in both datasets to be able to match the computed risk to the sample that is used for the structural analysis.

\footnotetext{
${ }^{13}$ When the NRA is 65 , the pensions of someone who retires at age 60 are deducted by $5 \cdot 3.6 \%=$ $18 \%$

${ }^{14}$ This is an annual survey that, since 1984, collects individual- and household-level information from about 12,000 households (Wagner et al., 2007).
} 
The associated risk of job loss depends on age, education, past year's log years of tenure and log monthly wages. Thus, the probability of job loss $\Phi_{i t}^{u}$ follows a logistic distribution $\Lambda($.$) with the following specification.$

$$
\begin{aligned}
\Phi_{i t}^{u} & =\Lambda\left(\alpha_{i}+\phi_{0}+\phi_{1} \text { age }_{i t}+\phi_{2} \mathbf{1}\left[\text { educ }_{i}=2\right]+\phi_{3} \mathbf{1}\left[e d u c_{i}=3\right]\right. \\
& \left.+\phi_{4} \log \left(\text { tenure }_{i t-1}\right)+\phi_{5} \ln \left(\text { wage }_{i t-1}\right)\right)
\end{aligned}
$$

where $\alpha_{i} \sim N\left(0, \sigma_{\alpha}^{2}\right)$ is an individual-specific random error. The variable educ is defined as 1 if years of education are lower than 12, 2 if years of education are 12 or more and lower than 16 years and 3 if years of education are 16 or more. That is, the baseline is low education.

\subsection{Value functions}

The maximization of the decision problem in Equation 1 requires the choice of an optimal sequence of $d_{t}$ from $t$ to $T$. Drawing on dynamic programming techniques (Bellman, 1957), the dynamic optimization problem can be broken down to a two-period problem by recursively defining it as a function of state-specific conditional value functions $V_{i t}\left(C_{i t}, \Gamma_{i t} \mid d_{i t}, \Omega_{i t}\right)$ which define the maximum present discounted value of the individual's future life-cycle utility, conditioned on the individual's choice $\left(d_{i t}\right)$ and state variables $\left(\Omega_{i t}\right)$. For the purpose of readability, I define: $V_{i t}^{d}(k)=V_{i t}\left(C_{i t}, \Gamma_{i t} \mid d_{i t}=d, \Omega_{i t}=\Omega\right)$ as the value function with choice $d$ in employment state $k$ (if one choice inherits different employment states) conditioned on other state variables. Furthermore, the method to condition on access to partial retirement produces two sets of value functions with different choice sets $D^{p}$ and $D^{n p}$. The choice-specific value functions are written as follows.

$$
\begin{aligned}
& V_{i t}^{f}\left(d_{i t} \in D^{p}\right)=U_{i t}^{f}(f)+\delta \pi_{t+1}\left[\Phi_{i t}^{u} \operatorname{Emax}\left\{V_{i t+1}^{r e}, V_{i t+1}^{r u}\right\}+\left(1-\Phi_{i t}^{u}\right) \operatorname{Emax}\{\right. \\
& \left.\left.\operatorname{Emax}\left\{V_{i t+1}^{r e}, V_{i t+1}^{r u}\right\}, \operatorname{Emax}\left\{V_{i t+1}^{p_{1}}, \cdots, V_{i t+1}^{p_{6}}\right\}, V_{i t+1}^{f}\right\}\right] \\
& V_{i t}^{p_{a}}=\sum_{j=t}^{t+a} \delta^{j-t} \pi_{j}^{\mathbf{1}(j \neq t)} U_{i j}^{p_{a}}(p)+\sum_{j=t+a+1}^{T} \delta^{j-t} \pi_{j} U_{i j}^{p_{a}}(r), \text { where } a \in\{1, \cdots, 6\} \\
& V_{i t}^{r u}=\sum_{j=t}^{t+a} \delta^{j-t} \pi_{j}^{\mathbf{1}(j \neq t)} U_{i j}^{r u_{a}}(u)+\sum_{j=t+a+1}^{T} \delta^{j-t} \pi_{j} U_{i j}^{r u_{a}}(r), \text { where } a \in\{1, \cdots, 3\} \\
& V_{i t}^{r e}=\sum_{j=t}^{T} \delta^{j-t} \pi_{j}^{\mathbf{1}(j \neq t)} U_{i j}^{r e e_{a}}(r)
\end{aligned}
$$

The value function for full-time employment when there is no access to partial retirement is written as: 


$$
\begin{gathered}
V_{i t}^{f}\left(d_{i t} \in D^{n p}\right)=U_{i t}^{f}(f)+\delta \pi_{t+1}\left[\Phi_{i t}^{u} \operatorname{Emax}\left\{V_{i t+1}^{r e}, V_{i t+1}^{r u}\right\}+\left(1-\Phi_{i t}^{u}\right) \operatorname{Emax}\{\right. \\
\left.\left.\operatorname{Emax}\left\{V_{i t+1}^{r e}, V_{i t+1}^{r u}\right\}, V_{i t+1}^{f}\right\}\right]
\end{gathered}
$$

Furthermore, there is no value function for the partial retirement choice when there is no access to partial retirement and the remaining value functions do not differ under both choice sets.

\subsection{Solution and estimation}

Due to the finite horizon of the choice problem, the solution can be derived by backwards induction starting from the utility flow in the final decision period. Within the model's framework, the individual will eventually have to retire. After choosing one of the potential exit options, the individual receives (depending on the choice either immediately, after a period of partial retirement or after a period of unemployment insurance claiming) an annual pension according to Equation 8 up to the final period. It follows from the type I extreme value distribution of $\epsilon_{i t}\left(d_{i t}\right)$ in the utility function that we can derive a closed form solution for the expected maximum of choice-specific value functions (Rust, 1987) such that for any value function specific to the choices $l \neq m$

$$
E \max \left\{V^{l}, V^{m}\right\}=\ln \left(\exp \left(V^{l}\right)+\exp \left(V^{m}\right)\right)+\gamma
$$

where $\gamma$ represents the Euler-Mascharoni constant with $\gamma \approx 0.5772$. Moreover, with the assumption of additive separability over time and conditional independence (Rust, 1987), the model produces choice probabilities equal to

$$
P\left(\max \left(V_{i t}^{d}\right)=V_{i t}^{\bar{d}}\right)=\frac{\exp \left(V_{i t}^{\bar{d}}\right)}{\sum_{j \in D^{p}} \exp \left(V_{i t}^{j}\right)}
$$

and

$$
P\left(\max \left(V_{i t}^{d}\right)=V_{i t}^{\bar{d}}\right)=\frac{\exp \left(V_{i t}^{\bar{d}}\right)}{\sum_{j \in D^{n p}} \exp \left(V_{i t}^{j}\right)}
$$

The probability to observe a choice needs to be adjusted by the unemployment probability $\Phi_{i t}^{u}$ which yields

$$
\begin{aligned}
& P\left(d_{i t}=f\right)=\left(1-\Phi_{i t}^{u}\right) \cdot P\left(V^{f}>V^{r} \wedge V^{f}>V^{p}\right) \\
& P\left(d_{i t}=p_{\bar{a}}\right)=\left(1-\Phi_{i t}^{u}\right) \cdot P\left(V^{p}>V^{r} \wedge V^{p}>V^{f}\right) \cdot P\left(\max \left(V_{i t}^{p_{a}}\right)=V_{i t}^{p \bar{a}}\right) \\
& P\left(d_{i t}=r u\right)=\left(\Phi_{i t}^{u}+\left(1-\Phi_{i t}^{u}\right) \cdot P\left(V^{r}>V^{p} \wedge V^{r}>V^{f}\right)\right) \cdot P\left(V^{r u}>V^{r e}\right) \\
& P\left(d_{i t}=r e\right)=\left(\Phi_{i t}^{u}+\left(1-\Phi_{i t}^{u}\right) \cdot P\left(V^{r}>V^{p} \wedge V^{r}>V^{f}\right)\right) \cdot P\left(V^{r e}>V^{r u}\right)
\end{aligned}
$$


where $V^{r}=E \max \left\{V^{r u}, V^{r e}\right\}$. The choice probabilities with the choice set $D^{n p}$ are computed analogously. Taking the product of the model's choice probabilities over observed choices produces the conditional individual likelihoods $L_{i}\left(D^{p}\right)=$

$\prod_{t=1}^{\tilde{t}-1} P\left(d_{i t}=f\right) \cdot P\left(d_{i \tilde{t}} \neq f\right)$ and $L_{i}\left(D^{n p}\right)$, analogously, where $\tilde{t}$ represents the period in which the exit decision is made. The final log-likelihood is written as

$$
L L=\sum_{i=1}^{N^{p}} \log \left(L_{i}\left(D^{p}\right)\right)+\sum_{i=1}^{N^{n p}} \log \left(\Phi_{i}^{p} \cdot L_{i}\left(D^{p}\right)+\left(1-\Phi_{i t}^{p}\right) \cdot L_{i t}\left(D^{n p}\right)\right.
$$

where $N^{p}$ and $N^{n p}$ represent the number of individuals where the partial retirement decision is observed and where it is not observed, respectively. Parameters $\left(s u b^{w}, s u b^{r}, \pi_{t}, \delta, g, \Phi_{i}^{p}\right)$ are set in advance, $\Phi_{i t}^{u}$ is estimated in a first step using a logit model, and the parameters $(\rho, \gamma, \lambda, \theta, v)$ are estimated with the structural model using maximum-likelihood estimation.

\section{Data and descriptive analysis}

This paper relies on the administrative Biographical Data of Social Insurance Agencies in Germany (BASiD). The data is a combination of two administrative datasets from the Statutory Pension Insurance and the Federal Employment Agency through the identical social security number that serves as the unique individual identifier (Hochfellner et al., 2012). The basis of this dataset is a random selection from the Sample of Insured Persons and their Insurance Accounts (VSKT) of the Statutory Pension Insurance, which was enriched with individual information from the Federal Employment Agency. The joint dataset provides spell information about the employment history for each individual on a daily level from first entry through 2007. The sample covers the cohorts 1940-1947. In addition, BASiD contains information about education as well as several individual and work-related characteristics. To avoid dropping much of the sample due to a high degree of missings in the education variable, I impute lacking educational information using the method suggested by Fitzenberger et al. (2005).

What distinguishes BASiD from other administrative datasources is the combination of full individual employment histories and information on pension take-up from the Statutory Pension Insurance with the information on partial retirement take-up from the Federal Employment Agency. The administrative reporting of all contributors earnings biographies ensures a high reliability on earnings information. This constitutes a clear advantage over survey data since reported data on earnings and employment histories or education usually suffers from non-response or reporting bias.

Earnings information in German administrative records are top-coded since contributions to social security and pension are deducted as a share of earnings up to an annually specified wage ceiling as suggested by (Bönke et al., 2015). Since earnings beyond that wage ceiling are recorded as exactly equal to that limit, wage information in the present dataset are right-censored. In order to obtain a better approximation 
of the true distribution of earnings, individual earnings that are affected by topcoding are imputed based on a Pareto rule for each year with the censoring limit set to the respective annual wage ceiling. A more detailed description of the imputation is given in Appendix C.

I focus on West German men, who constitute the largest group of workers in partial retirement. The number of women in the studied cohorts eligible to partial retirement take-up is comparatively small, with earnings- and employment histories considerably different between East and West Germans in the studied time interval (Huber et al., 2016). Furthermore, I set the panel level of the dataset to annual observations. However, the loss in information compared to the drastic reduction in the computational burden, as we move from daily to annual intervals, is small, since most individuals implement retirement decisions exactly on their birthdays, as shown in Figure 2, and partial retirement take-up mostly occurs in full years, as seen in Figure 7 in Appendix D. Moreover, due to lacking information on health, I exempt individuals who are eligible for either of the two disability pensions types. The missing health information makes it difficult to account for the effect of health shocks on the studied retirement decisions, which is why individuals subject to particularly strong health shocks are excluded. Furthermore, I restrict to a minimum of five contribution years to the pension fund due to the institutional restriction on pension eligibility. Finally, individuals need to be in full-time employment subject to social security contributions at age 54 with at least two years of tenure. This is done in order to correct for workers selecting into firms with partial retirement only because they are able to enter partial retirement shortly after joining the firm. Refraining from this restriction could potentially yield an over-representation of individuals with strong partial retirement preferences, which could result in an upwards biased estimation of partial retirement preferences (Huber et al., 2016). Further, this restriction ensures eligibility for unemployment insurance receipt prior to retirement, such that the retirement path via unemployment is a viable alternative to partial retirement. Thus, these restrictions produce a homogeneous group of people who all fulfill the eligibility criteria for the studied retirement options.

The final sample consists of 3,188 individuals with observed retirement entries. Of those, about $39 \%(1,246)$ enter old-age retirement directly after work, $29 \%$ (910) after unemployment, and 32\% (1032) after partial retirement. Since the estimation strategy allows the inclusion of right-censored observations in a panel data setting, the sample on which the analysis is based further includes employment decisions of 2,238 additional individuals for whom the retirement decision is not observed. 
Table 1: Descriptive statistics by retirement path

\begin{tabular}{lcccccc}
\hline & \multicolumn{2}{c}{ Regular } & \multicolumn{2}{c}{ Unemployment } & \multicolumn{2}{c}{ Partial } \\
\hline & Mean & Std.Dev. & Mean & Std.Dev. & Mean & Std.Dev \\
\hline Retirement age & 64.123 & 0.872 & 60.995 & 1.228 & 61.316 & 1.308 \\
Pension (mon) & 1365.597 & 363.975 & 1128.939 & 265.997 & 1254.981 & 247.331 \\
Pension points & 54.426 & 14.431 & 51.851 & 11.302 & 56.315 & 10.083 \\
Contribution years & 44.791 & 6.759 & 43.533 & 4.980 & 44.281 & 4.197 \\
German & 0.812 & 0.391 & 0.843 & 0.364 & 0.872 & 0.334 \\
Education low & 0.091 & 0.288 & 0.108 & 0.310 & 0.078 & 0.269 \\
Education interm. & 0.697 & 0.516 & 0.760 & 0.480 & 0.775 & 0.473 \\
Education high & 0.211 & 0.434 & 0.132 & 0.351 & 0.146 & 0.368 \\
$\mathbf{U}_{p} r$ & 0.009 & 0.015 & 0.022 & 0.033 & 0.015 & 0.024 \\
\hline $\mathbf{N}$ & 1246 & & 910 & & 1032 & \\
\hline
\end{tabular}

Source: Own calculations based on BASiD. "Partial" stands for partial retirement.

Table 1 shows the group means and standard deviations for relevant variables by retirement paths. It can be seen that institutional retirement age thresholds are binding since regular retirees enter retirement much later than those who retire via unemployment or partial retirement given the early retirement option for non-regular retirement paths. Despite this earlier retirement age for partial retirees, they collect, on average, more pension points than the other two groups suggesting that the share of partial retirement retirees is higher in higher paying jobs. This is in line with Chen and Scott (2006), who show that individuals with the option for partial retirement generally have a higher socio-economic background. This is further supported by the slightly higher education, share of German citizenship, pensions, and contribution years for partial retirement retirees compared to unemployment retirees. However, despite the higher average pension points for partial retirement retirees, regular retirees receive a slightly higher monthly pension on average. This can be explained by the lower retirement age and the corresponding deductions to pensions.

The fact that retirement decisions are -to a large extent- driven by institutional age thresholds is supported by Figure 2 since the peak values for retirement entry occur at ages 60 , the earliest possible retirement age for partial or unemployment retirees, 63 , the early retirement age for regular retirees, and 65, the normal retirement age. 
Figure 2: Retirement entry by age

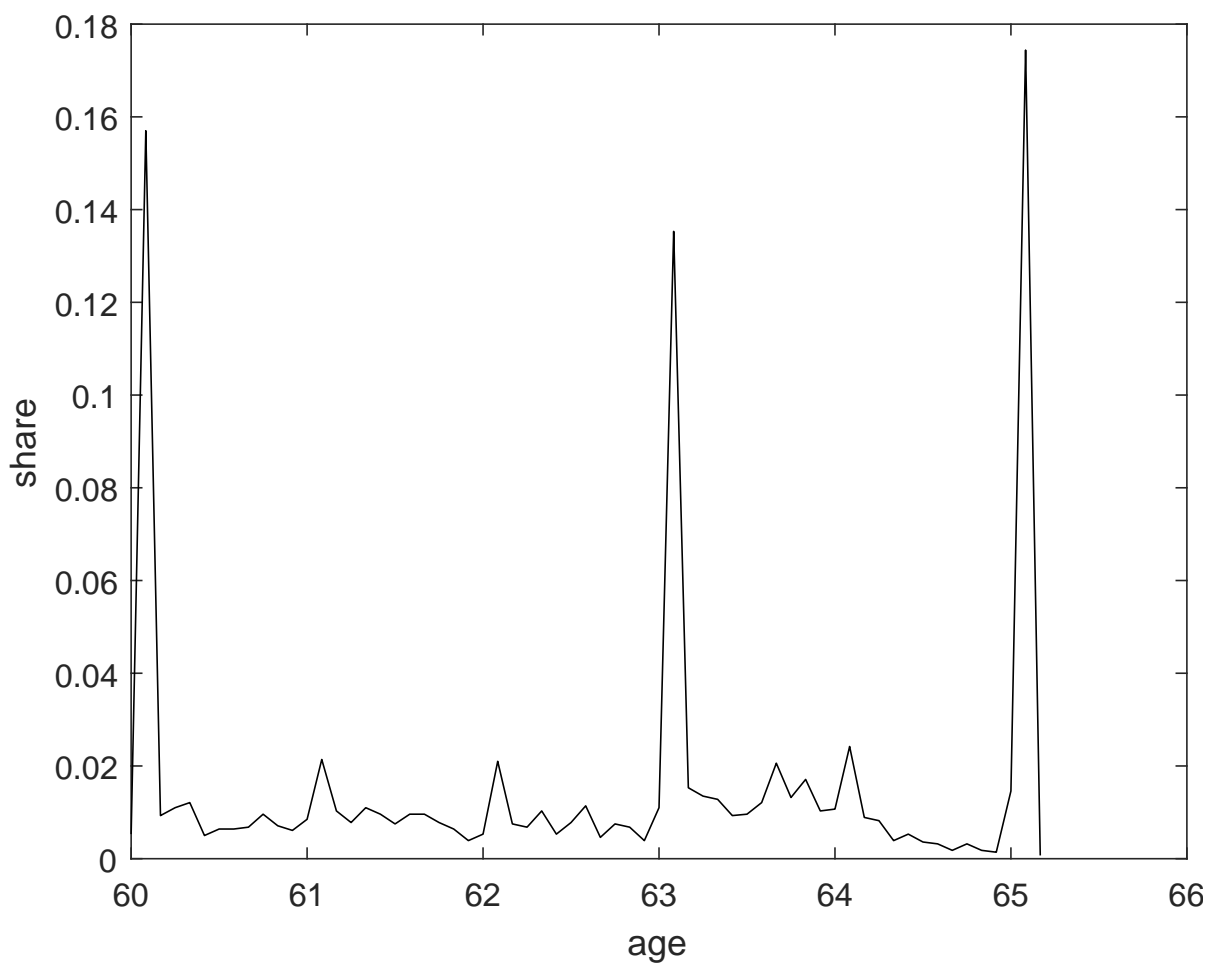

Source: Own calculations based on BASiD sample with monthly observations. Sample restrictions: Only validated accounts, no disability insurance receipt, at least five pension contribution years, at least two years tenure at age 54 .

Figure 3: Relative shares in non-employment by age and retirement path

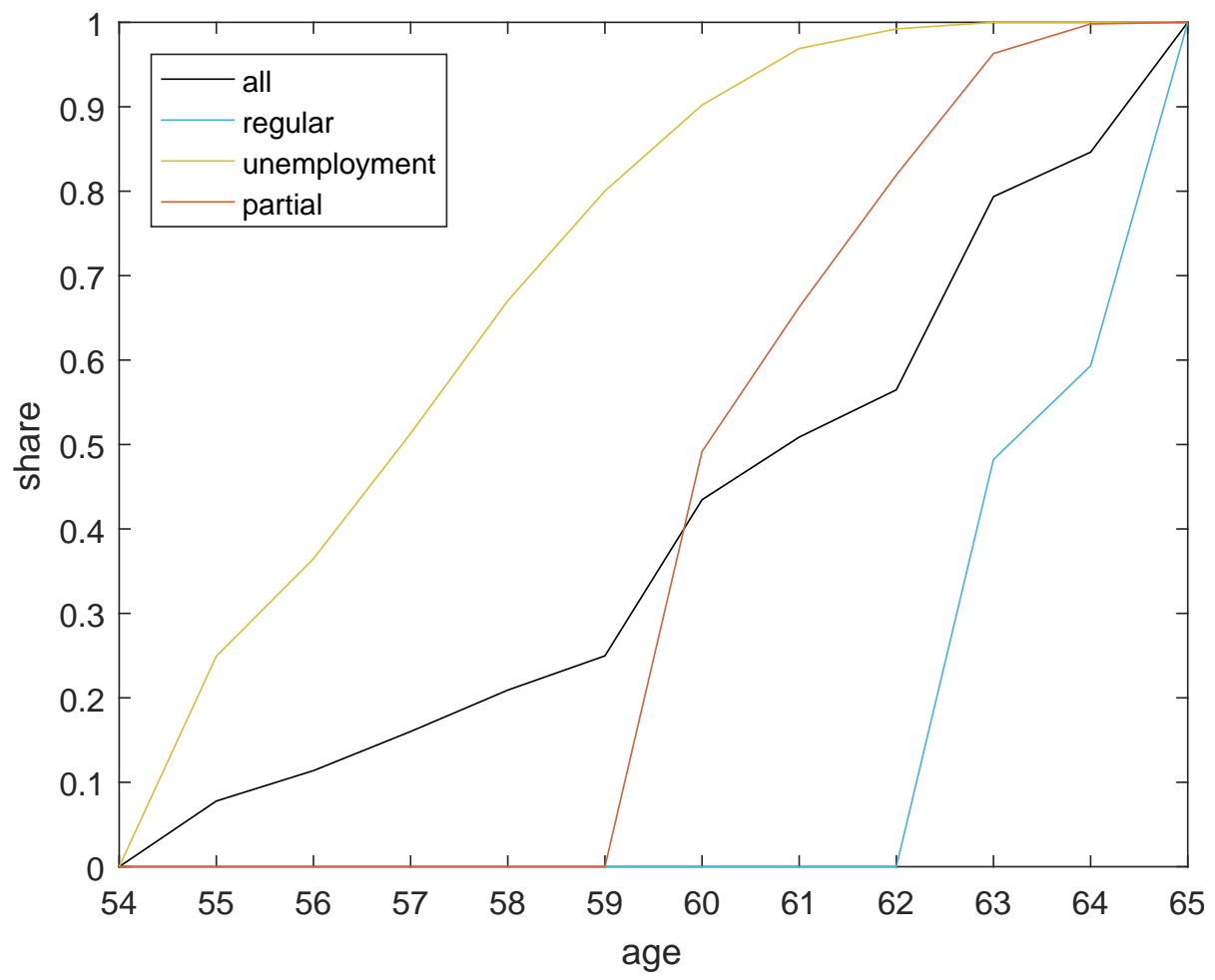

Source: Own calculations based on BASiD. Shares are relative to the retirement path group size. 
Finally, Figure 3 shows the share of individuals in non-employment relative to the number of people in the respective retirement paths. Generally, the status "nonemployed" is defined as being unemployed or in retirement. The figure shows that partial retirees leave the employment status earlier than regular retirees but later than unemployment retirees. Thus, this suggests that a shift from regular retirement to partial retirement would generate negative employment effects while a shift from retirement via unemployment to retirement via partial retirement would generate positive employment effects.

\section{Results}

In this section I subsequently discuss the results from the estimation of the job loss risk, the structural estimation and the goodness of fit of the structural model.

\subsection{Job loss risk}

Table 2 shows the marginal effects on the probability of becoming involuntarily unemployed from the logit model that is described in Equation 9.

Table 2: Logit, marginal effects, job loss risk

\begin{tabular}{lcc}
\hline & Value & Std.Err \\
\hline$\phi_{1}($ age $)$ & $-0.0146^{* * *}$ & 0.0017 \\
$\phi_{2}($ educ=2) & $-0.4375^{* * *}$ & 0.0487 \\
$\phi_{3}($ educ=3) & $-0.3337^{* * *}$ & 0.0758 \\
$\phi_{4}($ log $($ tenure $))$ & $-0.3268^{* * *}$ & 0.0126 \\
$\phi_{5}($ log $($ wage $))$ & $-0.0914^{* *}$ & 0.0395 \\
$\phi_{0}($ constant $)$ & $-1.7658^{* * *}$ & 0.2852 \\
\hline$\sigma_{\alpha}$ & 0.9951 \\
$\mathbf{N}$ & 90,723 \\
log-likelihood & $-16,636$ \\
\hline \multirow{3}{*}{${ }^{* * *}$ and ${ }^{* * *}$ denote significance level of $10 \%, 5 \%$} \\
and 1\%, respectively. \\
\end{tabular}

The estimation is based on a sample of all West German men in the SOEP excluding civil servants, self-employed and pensioners and the results are matched to the equivalent sample in BASiD. As expected, the risk of involuntary job-loss decreases with age. One reason for this could be that higher job-protection for people with higher tenure reduces the probability of job-loss due to the expiration of a temporary contract or firing as people get older. As expected, the job-loss risk also decreases with 
wage, education and tenure since better educated individuals in higher paid jobs with more tenure are less likely to risk involuntary job loss. Overall, the unemployment risk ranges between virtually 0 and $10 \%$.

\subsection{Model estimates}

Table 3 shows the results from the structural estimation of the model. Due to the separate identification problem between time and risk preferences (Rust, 1994), I set the discount factor $\delta$ to 0.96, as identified by Gourinchas and Parker (2002) in a consumption life-cycle model. Overall, I find reasonable and precise estimates of the structural parameters that are consistent with the present literature. I obtain an estimate of 2.9988 for $\rho$, the coefficient of relative risk aversion. This is above the 1.81 as found in the retirement model by Blau and Gilleskie (2006) but far below 5 as estimated in the model by French and Jones (2011). Given that the baseline employment status is full-time employment, the preferences for the other employment states, which yield more leisure, are positive.

Table 3: Structural parameters

\begin{tabular}{lcc}
\hline & Value & Std.Err \\
\hline Utility function & & \\
$\beta$ & 0.96 & - \\
$\rho$ & $2.9988^{* * *}$ & 0.1729 \\
Retirement & & \\
$\lambda_{0}$ & $0.8532^{* * *}$ & 0.0280 \\
$\lambda_{1}$ & $0.0087^{* *}$ & 0.0037 \\
Partial retirement & & \\
$\theta_{0}$ & $1.2616^{* * *}$ & 0.0234 \\
$\theta_{1}$ & $-0.5856^{* * *}$ & 0.0318 \\
Unemployment & & \\
$v_{0}$ & $1.2226^{* * *}$ & 0.0320 \\
$v_{1}$ & $-0.8413^{* * *}$ & 0.0599 \\
\hline$l l$ & $-14,861$ \\
\hline \hline
\end{tabular}

Before people can enter retirement at age 60, leisure in unemployment and partial retirement is valued more positively than retirement. The preference for partial retirement before age 60 is strongly positive with a value of 1.26 but it decreases by 0.59 once people can enter retirement. This suggests that individuals are likely to forego 
higher earnings in full-time employment for the benefits of part-time employment in the given partial retirement program. At the same time, this also shows that people tend to opt for full retirement once the option occurs. Similarly, people experience leisure in unemployment positively (with a parameter value of 1.22) before they can enter retirement since this is the only option to fully reduce employment efforts for individuals younger than 60 . At age 60 these preferences reduce by a value of 0.84 which is a more substantial drop than the reduction of partial retirement preferences. This is in line with the stigma in unemployment insurance receipt as mentioned in the model section. As expected, the preference for retirement is positive with a value of 0.85 and slightly increasing by a value of about 0.01 per year. ${ }^{15}$

\subsection{Model fit}

Based on the estimation of structural parameters and random draws from the income distribution within the data, I simulate a dataset with 100,000 observations. Figure 4 shows how well the simulated dataset fits the real dataset by comparing the shares in each employment state by age in the present and the simulated dataset. ${ }^{16}$

The overall pattern of individuals in each employment state is fitted reasonably well. The model slightly overpredicts the decrease in full-time employment at age 64 and correspondingly slightly overpredicts the increase in retirement or non-employment at age 64 . This is because the model does account for the institutionally driven increase in retirement rates from age 63 but not for the observed differences in retirement entries between age 63 and 64 as seen in Figure 2. Similarly, the decrease in partial retirement at ages 60-62 is a bit over-predicted. Finally, the model slightly overpredicts unemployment shares overall although the shape of the distribution across ages appears to be fitted relatively well. Overall, the simulated sample provides a reliable basis for further policy analysis.

\footnotetext{
${ }^{15}$ Deteriorating health with age is a main reason to allow for increasing retirement preferences. The sample is restricted to more healthy individuals without disability benefits eligibility which explains why the positive trend in the retirement preference is relatively small.

${ }^{16}$ For full-time employment it is equal to one at age 54 and for retirement it is equal to one at age 65 because of the model conditions on everyone being in full-time employment at the beginning of the decision period and everyone being retired at age 65. Therefore, the share of full-time employees is always decreasing while the share of individuals in retirement or non-employment is always increasing.
} 
Figure 4: Model fit

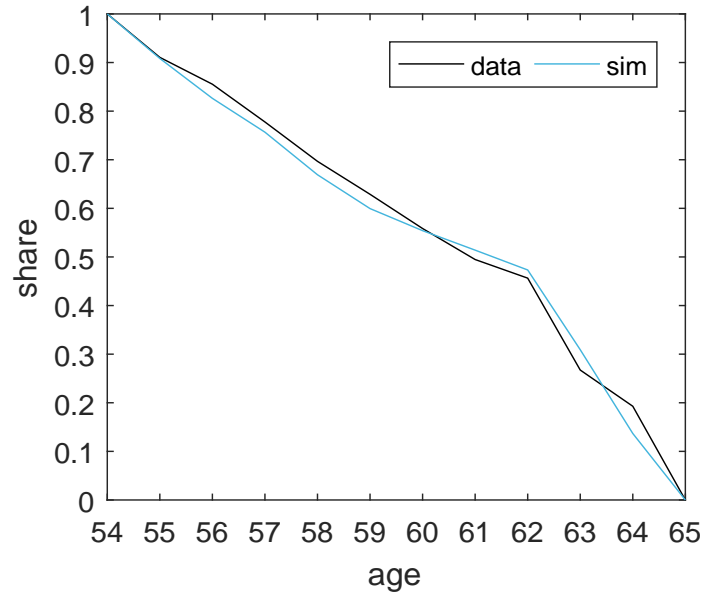

(a) Full-time

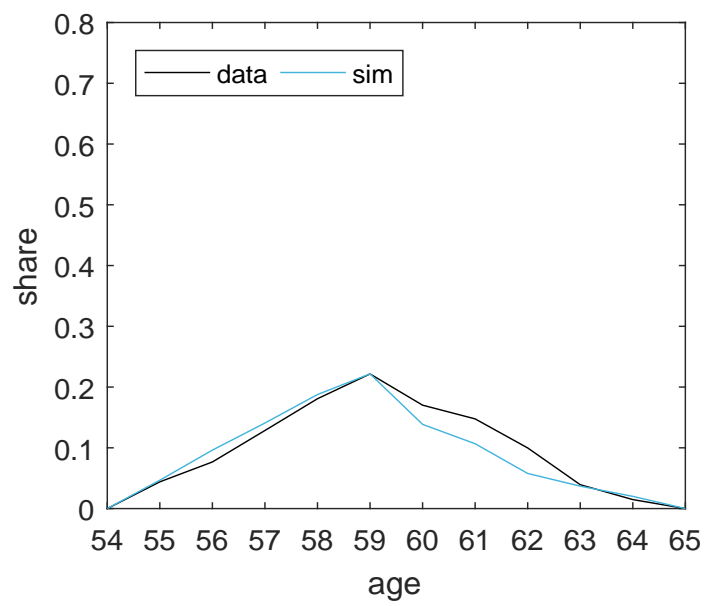

(c) Partial Retirement

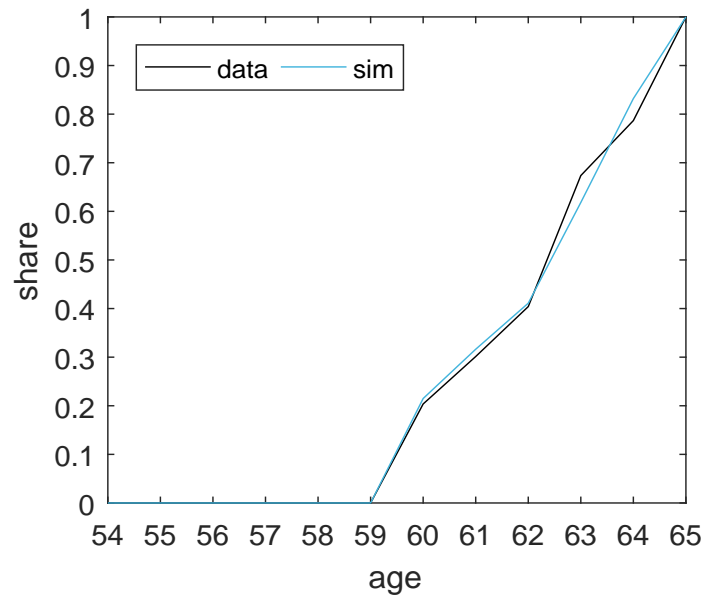

(b) Retirement

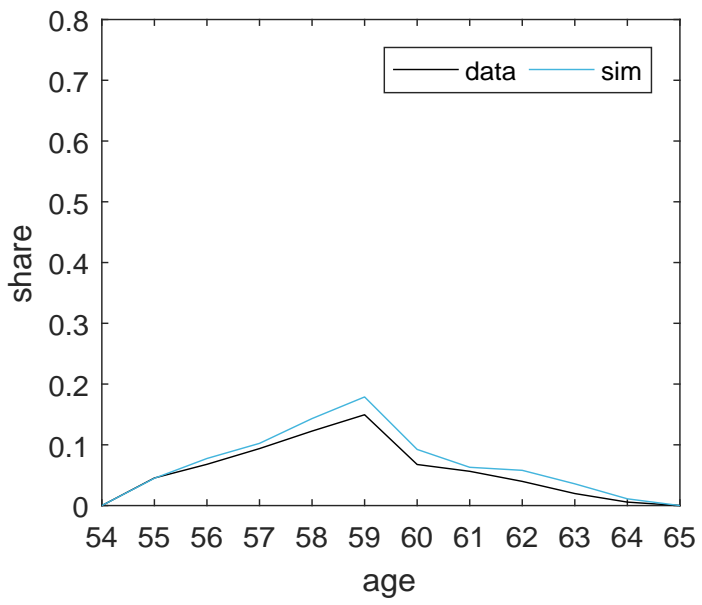

(d) Unemployment

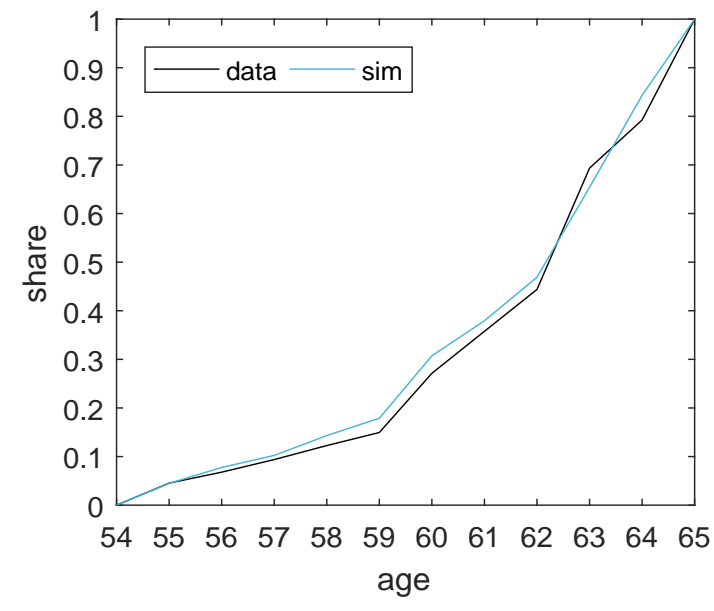

(e) Non-employment

Source: Own calculations based on BASiD. Based on 100,000 simulated observations. Figure depicts shares in each employment state by age. Sample is conditioned to $100 \%$ full-time employment at age 54 and $100 \%$ retirement at age 65 


\section{Policy simulations}

In this section, I present the results of counterfactual policy simulations that are performed based on the estimated parameters. Note that the institutional settings in the present data comprise different early retirement age thresholds for the studied retirement paths, an intermediate degree of access to partial retirement, and some specified financial incentives for partial retirement. For instance, in the underlying institutional setting, people become eligible for full retirement after partial retirement at the age of 60, while eligibility for regular retirement only starts at age 63 . Using this as a benchmark in the planned policy simulations would make it difficult to reveal the effects that derive purely from partial retirement. Therefore, for the baseline scenario, I adjust the early retirement age threshold for retirees after unemployment and partial retirement (60) to the early retirement age threshold of regular retirees (63). Moreover, the baseline scenario has neither a partial retirement option nor subsidies for partial retirement. This is done in order to understand the isolated effect of each policy simulation. I then analyze the effects of the following policy scenarios: (1) full access to partial retirement, (2) an increase in the NRA from 65 to 67, and (3) subsidies for wages and pension accrual for partial retirement. Note that in order to understand the combined effects from these policies, some analysis also covers the interaction of these policies. In the following sections, I start with a discussion of the employment effects. This is followed by a discussion of the fiscal consequences and distributional effects of each policy simulation.

\subsection{Employment effects}

I compute the effect of partial retirement on working life duration as well as employment volume. For a better measurement of changes in working life duration, I distinguish between retirement entry (pension receipt) and employment exit (entry into unemployment or retirement). In order to measure the effects on employment volume, I compute the full-time equivalent (FTE) at every age where one year in partial retirement is counted as $\frac{1}{2} * F T E .{ }^{17}$ In order to understand what drives these employment effects, I further depict changes in retirement path shares as well as changes in average shares of each employment state.

\subsubsection{Introducing partial retirement}

Figure 5 shows the effects on each employment status by age, from simulating full access to partial retirement compared to the baseline with no access to partial retirement. As expected, this leads to a significant increase in partial retirees at each age $(5(\mathrm{c}))$, which corresponds to a decrease in unemployment shares $(5(\mathrm{~d}))$ as well as individuals in full-time employment (5(a)). Thus, upon the introduction of partial retirement we observe both a shift to partial retirement from full-time employment as well as unemployment in old age.

\footnotetext{
${ }^{17}$ This corresponds to the definition of FTE in Gustman and Steinmeier (2008)
} 
Figure 5: Policy Simulation: 100\% access to partial retirement

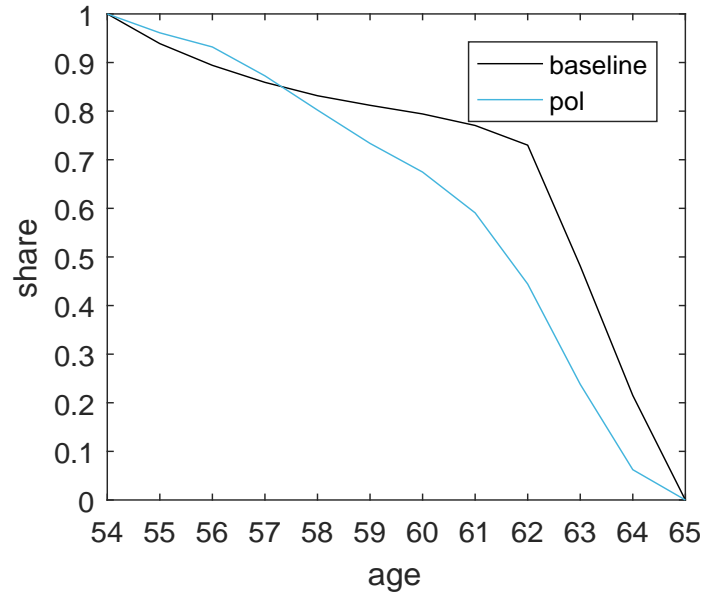

(a) Full-time

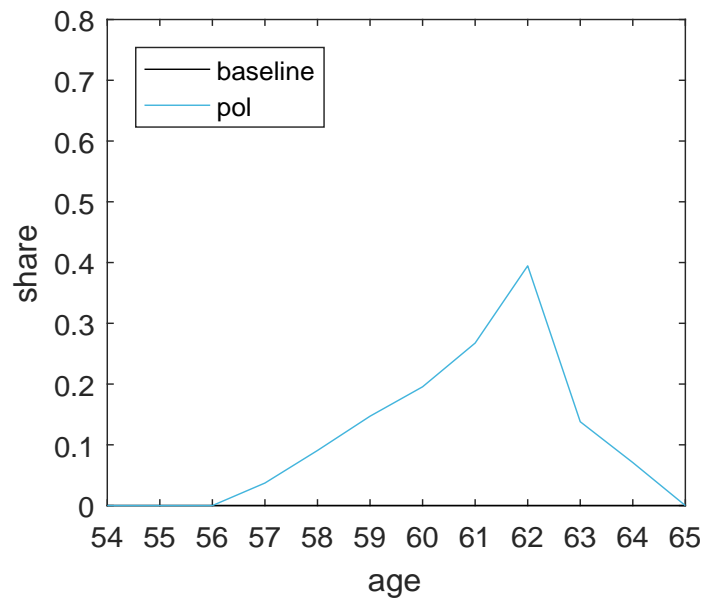

(c) Partial retirement

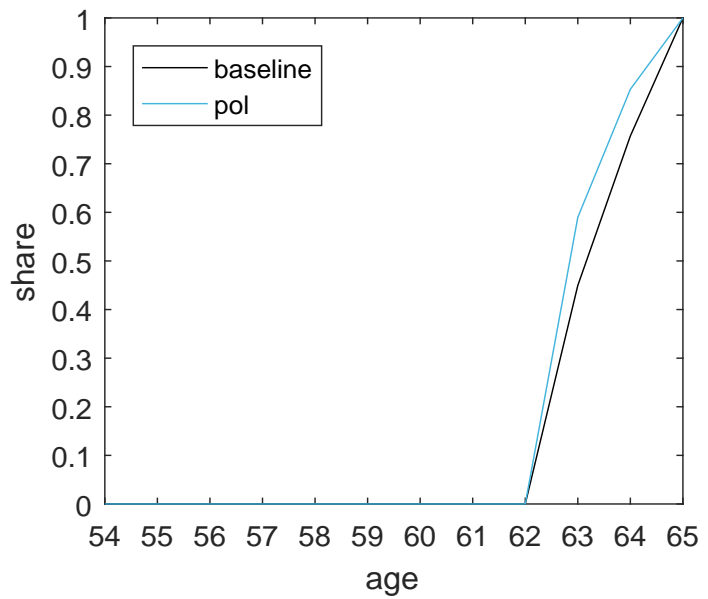

(b) Retirement

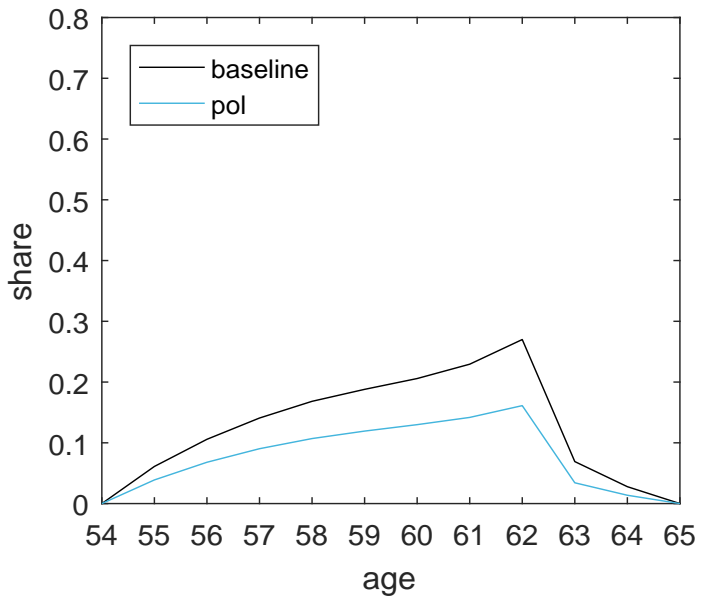

(d) Unemployment

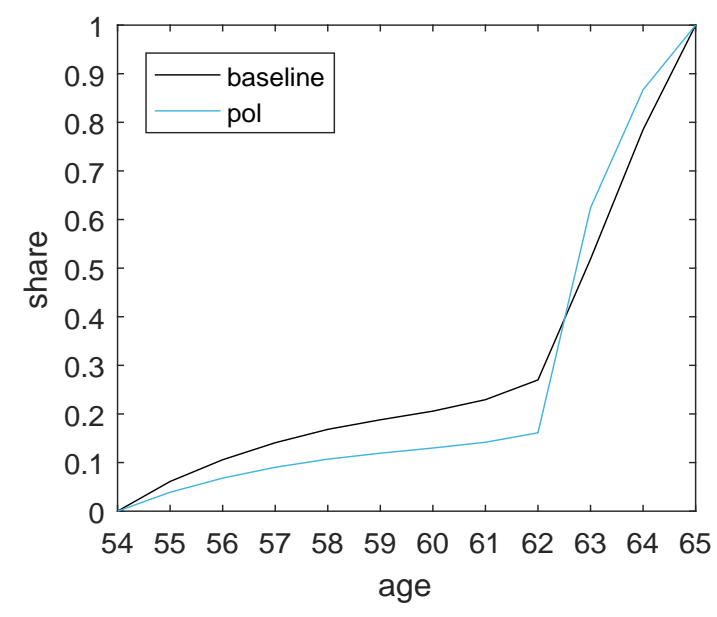

(e) Non-employment

Source: Own calculations based on BASiD. Based on 100,000 simulated observations. Figure depicts shares in each employment state by age. Sample is conditioned to $100 \%$ full-time employment at age 54 and $100 \%$ retirement at age 65 . 
Furthermore, it can be seen in Figure 5(b) that people enter retirement slightly earlier under a regime with partial retirement. More precisely, with partial retirement, a higher share of individuals enter retirement at age 63 and 64 compared to the retirement entry behavior without partial retirement. Thus, the additional time spent in partial retirement does not seem to postpone the timing of full retirement.

However, the working life duration still increases upon the introduction of partial retirement. This is because fewer people exit employment at younger ages, which can be seen in Figure 5(d). Until age 63, when people become eligible for regular retirement, there is a substantially lower share of people exiting employment under a partial retirement regime. From age 63 onwards there are slightly more people leaving employment due to the increased share of retirees at these ages. This suggests that partial retirement reduces the number of people who exit the labor market at younger ages through unemployment before they become eligible for regular retirement.

Table 4: Employment effects, partial retirement

\begin{tabular}{lcccc}
\hline & No part. ret. & Part. ret. & Diff & Diff (\%) \\
\hline Avg. retirement age & 63.79 & 63.56 & -0.24 & -0.37 \\
Avg. employment exit age & 62.33 & 62.65 & 0.33 & 0.52 \\
FTE avg. & 73.27 & 69.82 & -3.45 & -4.71 \\
\hline
\end{tabular}

Retirement path shares

\begin{tabular}{lcccc}
\hline Regular & 73.00 & 29.63 & -43.37 & -59.41 \\
Unemployment & 27.00 & 16.12 & -10.88 & -40.30 \\
Partial & 0.00 & 54.25 & 54.25 & - \\
\hline
\end{tabular}

Average share in employment state

\begin{tabular}{lcccc}
\hline Full-time & 73.27 & 63.11 & -10.16 & -13.86 \\
Partial & 0.00 & 13.41 & 13.41 & - \\
Unemployment & 14.66 & 9.04 & -5.62 & -38.32 \\
Retirement & 12.07 & 14.43 & 2.36 & 19.57 \\
\hline \hline
\end{tabular}

Source: Own calculations based on BASiD. Based on 100,000 simulated observations. FTE represents Full-time employment equivalent. Shares are represented in \%. Column 3 depicts absolute changes. Column 4 depicts relative changes.

Whether or not this policy yields a positive employment effect depends on the size of each movement from unemployment/early retirement to partial retirement or full- 
time employment to partial retirement. Table 4 shows a summary of average statistics describing the employment effects of the present policy simulation. Differences in statistics between the policies are reported in both absolute and relative changes. The lowest panel of Table 4 supports the findings from above. The share of full-time employees and the unemployed falls by about $14 \%$ and $38 \%$, respectively. The middle panel shows that this is driven by a partial retirement take-up rate of about $54 \%$. While the increase in the partial retirement path seems drastic, it is reasonable when considering that partial retirement take-up with $35 \%$ access, as in the policy scenario underlying the original data, is more than $30 \%$.

Moreover, the upper panel shows that, while average retirement age reduces by 0.24 years (about 2.8 months), the average age at labor market exit increases by about 4 months from 62.33 to 62.65 , which is mostly driven by fewer people leaving the labor market earlier through unemployment. That is, partial retirement leads to an extension of working lives. However, Table 4 shows that FTE employment decreases on average by $4.71 \%$. Thus, although partial retirement leads to an extension of working lives, the overall effect of partial retirement on employment volume is negative, because the additional time spent in partial retirement instead of non-employment dies nit compensate the crowd out from full-time employment. 


\subsubsection{Increasing normal retirement age to 67}

Table 5: Employment effects, partial retirement, NRA: 67

\begin{tabular}{lcccc}
\hline & No part. ret. & Part. ret. & Diff & Diff (\%) \\
\hline Avg. retirement age & 64.65 & 64.63 & -0.02 & -0.03 \\
Avg. employment exit age & 63.62 & 64.04 & 0.41 & 0.65 \\
FTE avg. & 71.85 & 69.08 & -2.77 & -3.86 \\
\hline
\end{tabular}

Retirement path shares

\begin{tabular}{lcccc}
\hline Regular & 76.96 & 38.77 & -38.19 & -49.62 \\
Unemployment & 23.04 & 12.55 & -10.49 & -45.53 \\
Partial & 0.00 & 48.68 & 48.68 & - \\
\hline
\end{tabular}

Average share in employment state

\begin{tabular}{lcccc}
\hline Full-time & 71.85 & 62.84 & -9.01 & -12.54 \\
Partial & 0.00 & 12.47 & 12.47 & - \\
Unemployment & 8.60 & 4.97 & -3.63 & -42.19 \\
Retirement & 19.55 & 19.73 & 0.18 & 0.92 \\
\hline \hline
\end{tabular}

Source: Own calculations based on BASiD. Based on 100,000 simulated observations. FTE represents Full-time employment equivalent. Shares are represented in \%

Here I analyze the role of partial retirement with an NRA at 67. As before, the ERA is at 63 but pension receipt at 63 now yields four (instead of before two) years worth of deductions to pension annuities, i.e. $(4 \cdot 3.6 \%=14.4 \%)$, because the NRA is increased by two years. As in the previous simulations, a large spike in partial retirement corresponds to reductions in unemployment and full-time employment. However, Figure 10(c) in Appendix D shows that at an NRA of 67 the take-up of partial retirement is lower at age 62 but higher between the ages 63 and 67 . This indicates that at an increased NRA partial retirement take-up is higher particularly in the years between the ERA and NRA. It explains why the average retirement age virtually does not change when partial retirement is introduced as is shown in Table 5. Naturally, the average retirement age without partial retirement (64.65) and with partial retirement (64.63) is higher than in the previous policy simulation, which is due to the simulated increase in the NRA. More importantly, the findings indicate that people bridge the longer time between ERA and NRA with partial retirement in order to enter retirement at the same time as in the counterfactual scenario without partial retirement and prevent higher deductions to their individual pensions. 
Similar to before, the average age at employment exit increases by almost 5 months from 63.62 to 64.04 due to the substitution of unemployment by partial retirement. The change in FTE employment when introducing partial retirement is still negative, but not as pronounced as under the NRA at 65 regime. This can be explained using the average full-time employment shares depicted in the lowest panel. When the NRA is at 67 , average full-time shares decrease by $12.54 \%$, compared to a $13.86 \%$ reduction when the NRA is at 65 . This is enforced by the longer take-up of partial retirement as mentioned above.

\subsubsection{Financial subsidies for partial retirement}

Since the model incorporates the tax and transfer system while distinguishing between financial and non-financial preferences, I am able to isolate the effect of subsidies in a partial retirement program. The simulation considers changes in immediate income in partial retirement through a wage subsidy as well as changes in long-run income through changes in the pension point accrual during partial retirement. The long-run differences in income affect the decision makers utility through the model's forward-looking perspective. I employ the wage and pension accrual subsidies that are used in the underlying German partial retirement policy (20\% for wages and $40 \%$ for pension point accrual). Moreover, note that the model further incorporates tax exemptions for the wage subsidy in partial retirement.

Figure 6 compares the policy with financial subsidies to the corresponding policy without financial subsidies. As expected, Figure 6(c) shows that subsidizing partial retirement clearly leads to a higher take-up of partial retirement at almost all ages. Further, Figures 6(a) and 6(d) show that the drops in both full-time employment and unemployment are correspondingly larger. In addition, the difference between subsidized and unsubsidized partial retirement is visibly higher for full-time employment shares than unemployment shares. In terms of employment effects, this suggests that subsidized partial retirement compared to unsubsidized partial retirement has a stronger negative effect due to its reduction in full-time employment than a positive effect due to its reduction in unemployment. 
Figure 6: Policy Simulation: Subsidies for partial retirement. NRA set to 67

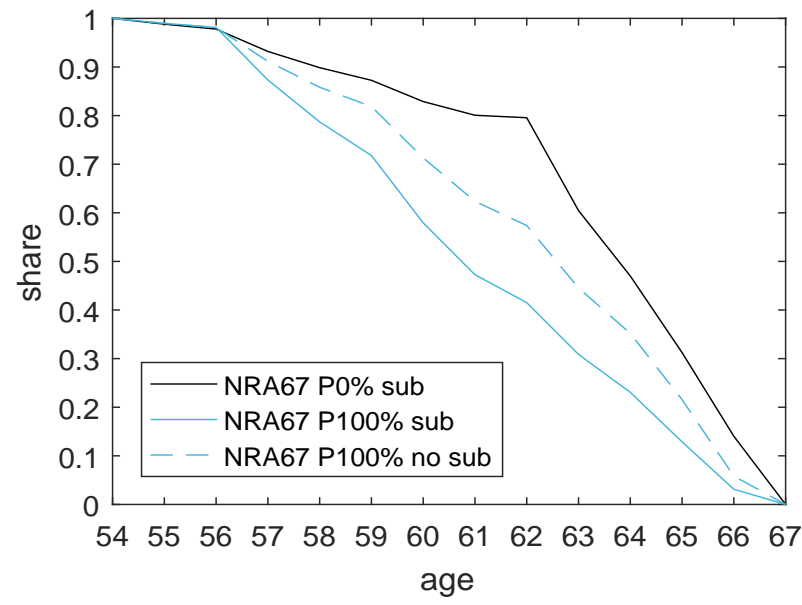

(a) Full-time

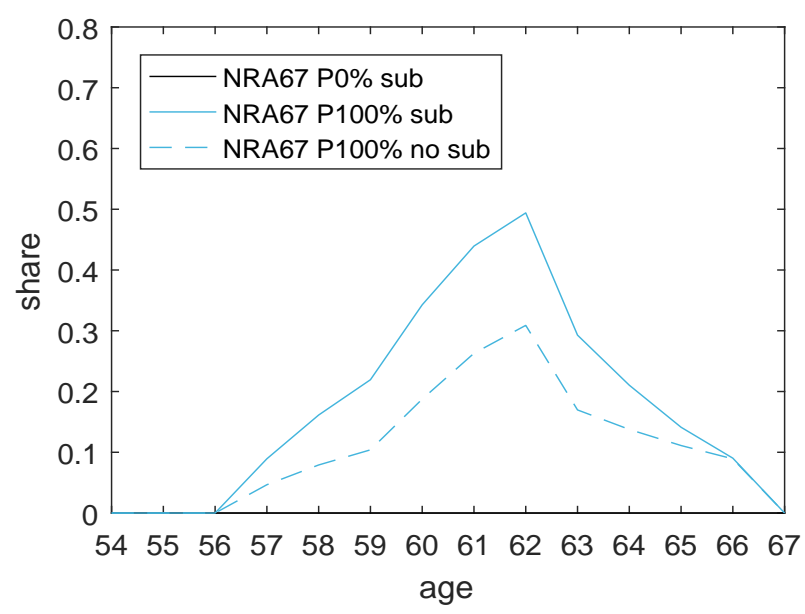

(c) Partial retirement

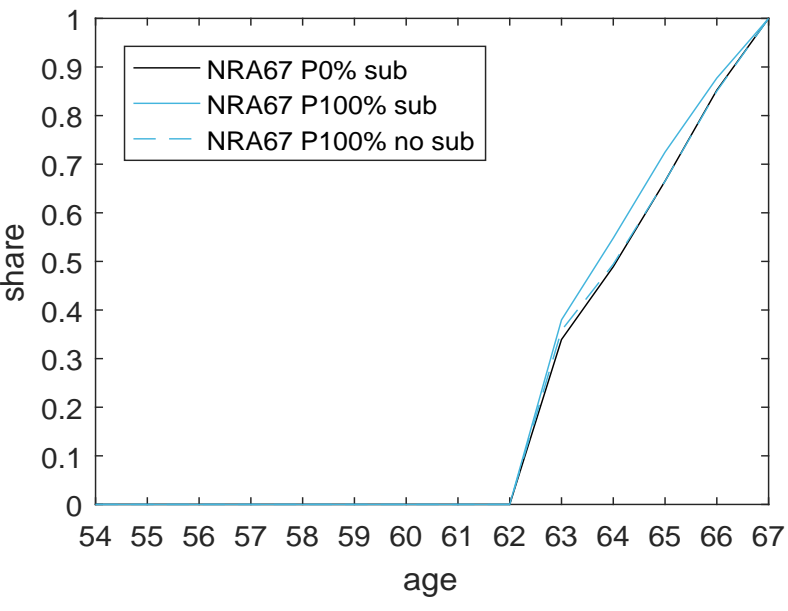

(b) Retirement

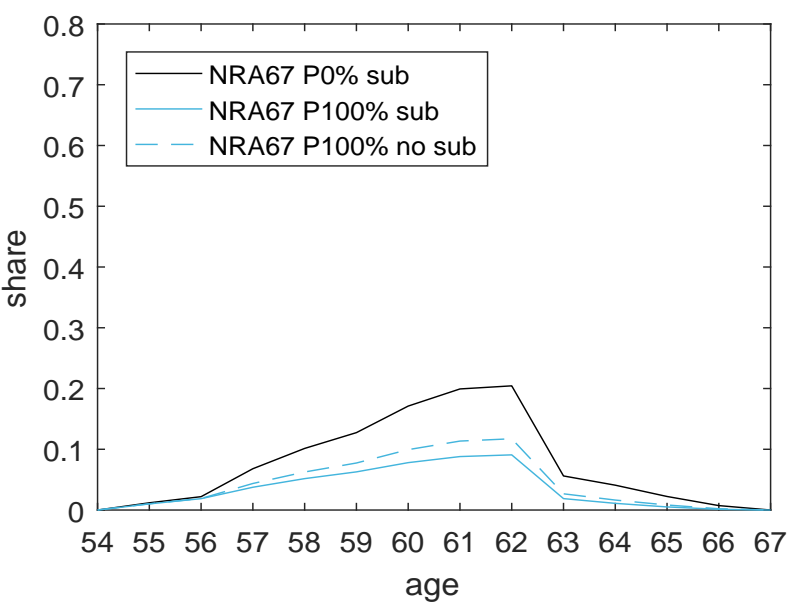

(d) Unemployment

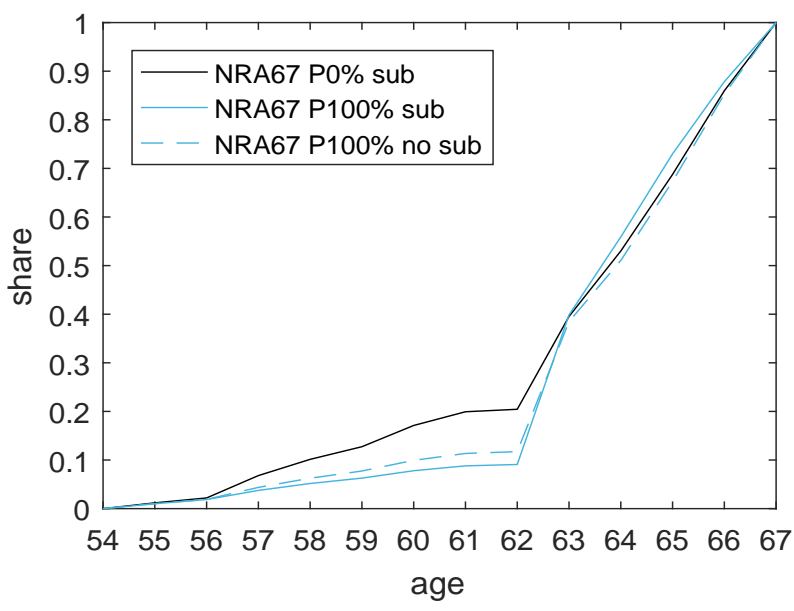

(e) Non-employment

Source: Own calculations based on BASiD. Based on 100,000 simulated observations. Figure depicts shares in each employment state by age. Sample is conditioned to $100 \%$ full-time employment at age 54 and $100 \%$ retirement at age 65 . 
Table 6, which compares summary statistics between scenarios with and without subsidized partial retirement, supports this finding. It can be seen that wage and pension compensations incentivize partial retirement since the share of people retiring via partial retirement increases by $66.37 \%$ compared to the $48.68 \%$ change in the scenario without subsidies (Table 5). Similarly the average share in the partial retirement state $(20.67 \%)$ is higher than the previous $12.47 \%$.

Furthermore, with subsidized partial retirement, the average age at employment exit increases by 4.4 months compared to 4.9 months in the case without subsidies. The corresponding reduction of the average retirement age from 64.65 to 64.47 (about two months) suggests that the additional people who substitute full-time employment by partial retirement due to the subsidies end up retiring earlier in partial retirement. Consequently, I find that the drop in employment volume due to partial retirement is larger when it is subsidized: the FTE employment drops in this case by about $10 \%$ compared to the $4 \%$ drop in the scenario without subsidies. This is because the additional share in partial retirement and the reduction in unemployment due to the subsidies does not make up for the additional reduction in full-time employment. Thus, compared to the scenario with unsubsidized partial retirement, I find overall more negative employment effects due to partial retirement.

Table 6: Employment effects partial retirement, NRA: 67, subsidies for partial retirement

\begin{tabular}{lcccc}
\hline & No part. ret. & Part. ret. & Diff & Diff (\%) \\
\hline Avg. retirement age & 64.65 & 64.47 & -0.18 & -0.28 \\
Avg. employment exit age & 63.62 & 64.00 & 0.37 & 0.59 \\
FTE avg. & 71.85 & 64.63 & -7.21 & -10.04 \\
\hline
\end{tabular}

Retirement path shares

\begin{tabular}{lcccc}
\hline Regular & 76.96 & 24.06 & -52.90 & -68.74 \\
Unemployment & 23.04 & 9.57 & -13.47 & -58.46 \\
Partial & 0.00 & 66.37 & 66.37 & - \\
\hline
\end{tabular}

Average share in employment state

\begin{tabular}{lcccc}
\hline Full-time & 71.85 & 54.30 & -17.55 & -24.43 \\
Partial & 0.00 & 20.67 & 20.67 & - \\
Unemployment & 8.60 & 3.95 & -4.65 & -54.10 \\
Retirement & 19.55 & 21.08 & 1.53 & 7.83 \\
\hline
\end{tabular}

Source: Own calculations based on BASiD. Based on 100,000 simulated observations. FTE represents Full-time employment equivalent. Shares are represented in percentages. 
To sum up, I find that partial retirement leads to an extension of working lives by about four to five months. However, the effect of partial retirement on labor supply is still negative although less so at a higher NRA because then individuals stay longer in partial retirement to avoid higher pension deductions. Subsidizing partial retirement yields even more negative employment effects.

\subsection{Fiscal consequences}

With the consideration of the underlying tax and transfer system as well as the simulation of counterfactual income streams for every policy simulation, I am able to analyze the fiscal consequences of each policy scenario. In this analysis, costs comprise unemployment insurance (UI) benefits, subsidies for partial retirement (P sub) as well as pension benefits (Pension). On the other side, public revenues comprise income tax (IT) and SSC. Since these costs and benefits from each individual vary across the respective employment states, the public budget varies with changes of the employment state distribution across different policy regimes. That is, each individual in the sample produces public costs and revenues in every period. Since it cannot be observed whose partial retirement compensations are subsidized by the federal employment agency, I assume an average subsidy rate of $18.5 \%$ of all partial retirement subsidies based on descriptive findings by Wanger (2009). All other changes in costs and revenues due to changes in employment states following a policy simulation are recorded within the model.

To illustrate the substantial difference in fiscal consequences for partial retirement with and without subsidies, I first start with an analysis of the effects with subsidies and then move to analyzing scenarios without subsidies. I collect costs and revenues in each period for each individual during its respective decision horizon. After labor market exit occurs, I take the present discounted sum of all future projected income streams that depend on the respective labor market exit and retirement age, chosen retirement paths, income levels, and collected pension points until the final period $T=100$. Survival probabilities apply as before. Since this analysis considers the government's perspective, I replace the individual discount factor with the interest rate $r=0.02$, which yields a government's discount factor of $\frac{1}{1+r} \approx 0.98$. This produces a lifetime balance for each individual for the simulated policy. Note that the decision period, as well as cost-benefit calculations, start at age 54 for every individual. 
Table 7: Fiscal consequences of partial retirement with partial retirement subsidies

\begin{tabular}{|c|c|c|c|c|c|c|}
\hline & \multicolumn{3}{|c|}{ Costs } & \multicolumn{2}{|c|}{ Benefits } & \multirow[b]{2}{*}{ Net balance } \\
\hline & Pension & UI & P sub & $\mathrm{SSC}$ & IT & \\
\hline \multicolumn{7}{|c|}{ ERA 63, NRA 65} \\
\hline No part. ret. & 364,840 & 12,882 & 0 & 106,210 & 56,584 & $-214,928$ \\
\hline Part. ret. & 366,560 & 6,220 & 2,418 & 99,148 & 50,529 & $-225,521$ \\
\hline Diff & 1,720 & $-6,662$ & 2,418 & $-7,062$ & $-6,055$ & $-10,593$ \\
\hline \multicolumn{7}{|c|}{ ERA 63, NRA 67} \\
\hline No Part. ret. & 350,170 & 9,148 & 0 & 115,200 & 64,299 & $-179,819$ \\
\hline Part.ret. & 352,840 & 4,146 & 2,781 & 106,090 & 56,705 & $-196,972$ \\
\hline Diff & 2,670 & $-5,002$ & 2,781 & $-9,110$ & $-7,594$ & $-17,153$ \\
\hline
\end{tabular}

Average cost and benefit units per person. Based on 100,000 simulated observations

Table 7 compares the average costs and benefits per unit per person between policy regimes without partial retirement access and regimes with full access to partial retirement. This is done for the cases with the NRA set to 65 and to 67 . In addition, partial retirement is subsidized in this case according to the underlying institutional settings. That is, wages in partial retirement are subsidized by $20 \%$ and pension point accrual during partial retirement by $40 \%$. Clearly, partial retirement with subsidies leads to a large reduction in net public balances.

In both scenarios, partial retirement largely reduces revenues from SSC and IT, which is mostly driven by the reduction in full-time employment when allowing for partial retirement, as shown above. Moreover, subsidies in wages during partial retirement lead to an average increase in partial retirement costs by about 2,600 $€$ in both cases. In contrast, the introduction of partial retirement leads to a decrease in average UI payments per person, by about $6,700 €$ per person when the NRA is at 65 and $5,000 €$ per person when the NRA is at 67 because partial retirement substitutes unemployment.

Overall, introducing partial retirement in case of the NRA at 65 reduces net public balances on average per person by $10,593 €$ while public balances reduce largely more (by $17,153 €$ on average per person) in case of the NRA at 67 . This is mostly driven by a larger substitution of full-time employment by partial retirement and correspondingly more pronounced reductions in SSC and IT. In addition, as shown above, the average retirement age drops less due to partial retirement when the NRA is at 67 which prevents high deductions to individual pensions. Therefore, pension payments increase more due to partial retirement when the NRA is at 67 (by 2,670€ per person) than when the NRA is at 65 (by 1,720€ per person). 
Table 8: Fiscal consequences of partial retirement, no subsidies for partial retirement

\begin{tabular}{|c|c|c|c|c|c|c|}
\hline & & Costs & & Ben & fits & \\
\hline & Pension & UI & ATZ sub & SSC & IT & Net balance \\
\hline \multicolumn{7}{|c|}{ ERA 63, NRA 65} \\
\hline No part. ret. & 364,840 & 12,882 & 0 & 106,210 & 56,584 & $-214,928$ \\
\hline Part. ret. & 361,140 & 7,856 & 0 & 101,410 & 51,637 & $-215,949$ \\
\hline Diff & $-3,700$ & $-5,026$ & 0 & $-4,800$ & $-4,947$ & $-1,021$ \\
\hline \multicolumn{7}{|c|}{ ERA 63, NRA 67} \\
\hline No Part. ret. & 350,170 & 9,148 & 0 & 115,200 & 64,299 & $-179,819$ \\
\hline Part. ret. & 348,250 & 5,190 & 0 & 110,590 & 59,380 & $-183,470$ \\
\hline Diff & $-1,920$ & $-3,958$ & 0 & $-4,610$ & $-4,919$ & $-3,651$ \\
\hline
\end{tabular}

Average cost and benefit units per person. Based on 100,000 simulated observations.

Table 8 shows the same analysis of fiscal consequences as before but without subsidies for partial retirement. Without subsidies, the negative effect on net balances from allowing for partial retirement reduces substantially to $1,021 €$ in case of the NRA at 65 and $3,651 €$ on average per person in case of the NRA at 67.

As before, the introduction of partial retirement leads to an average decrease per person in SSC and IT by $9,747 €(4,800+4,947)$ on average per person in case of the NRA at 65 and $9,529 €(4,610+4,919)$ in case of the NRA at 67 which are smaller effects than in the case with subsidies. At the same time, UI payments decrease by $5,026 €$ when the NRA is at 65 and $3,958 €$ on average per person when the NRA is at 67 . Thus, not paying subsidies reduces the drop in SSC and IT payments but also the drop in UI payments due to a lower substitution of full-time employment and unemployment.

Finally, it naturally cancels out any costs for wage subsidies and reverts the effect of partial retirement on pensions. That is, pensions reduce on average per person by $3,700 €$ when the NRA is at 65 and by $1,920 €$ when the NRA is at 67 . As before, the smaller reduction in pensions due to partial retirement when the NRA is at 67 is driven by the fact that the average retirement age changes less at an increased NRA which implies lower deductions to individual pensions and the collection of more pension points in the additional time until full retirement. Thus, individual pensions are less affected by partial retirement when the NRA is at 67 because people have more time to 'make up' for the loss in supplied work hours when switching to partial retirement.

To sum up, partial retirement has a negative effect on public balances due to reductions in IT and SSC. However, without subsidies, these negative effects reduce substantially by about $9,500 €$ to $13,500 €$ on average per person. 


\subsection{Distributional effects}

I base the analysis of distributional effects on pension payments since the underlying institutional settings yield pensions that reflect lifetime income better than employment earnings at any one point in time. Thus, I present distributional effects through deciles of realized annual pension payments and corresponding Gini coefficients for each policy simulation. As before, I start with analyzing the effects for policies with partial retirement subsidies and then move to policy scenarios without subsidies for partial retirement.

Table 9: Distributional effects in pensions, with subsidies for partial retirement

\begin{tabular}{|c|c|c|c|c|c|c|c|c|}
\hline \multicolumn{9}{|c|}{ Decile } \\
\hline & 1 & 2 & 3 & 5 & 7 & 8 & 9 & Gini coefficient \\
\hline \multicolumn{9}{|c|}{ ERA 63, NRA 65} \\
\hline No part. ret. & 10,406 & 12,077 & 13,196 & 15,188 & 17,119 & 18,107 & 19,240 & 25.46 \\
\hline Part. ret. & 10,796 & 12,243 & 13,185 & 15,031 & 17,005 & 17,969 & 19,007 & 24.18 \\
\hline Diff & 390 & 166 & -11 & -157 & -114 & -138 & -233 & -1.28 \\
\hline \multicolumn{9}{|c|}{ ERA 63, NRA 67} \\
\hline No Part. ret. & 10,290 & 11,962 & 13,014 & 14,782 & 16,562 & 17,499 & 18,666 & 24.90 \\
\hline Part.ret. & 10,695 & 12,166 & 12,970 & 14,709 & 16,556 & 17,502 & 18,643 & 24.12 \\
\hline Diff & 405 & 204 & -44 & -73 & -6 & 3 & -23 & -0.78 \\
\hline
\end{tabular}

Annual pension deciles. Based on 100,000 simulated observations. Gini coefficient is represented in percent.

Table 9 shows the distributional effects of partial retirement with the NRA at 65 in the upper panel and the NRA at 67 in the lower panel. The reduction in the Gini coefficient, by 1.28 percentage points with the NRA at 65 and by 0.78 percentage points with the NRA at 67 shows that introducing partial retirement reduces inequality in pension incomes. This result is independent of the NRA. Furthermore, we can see that partial retirement with subsidies leads to an increase in annual pensions for low deciles but a decrease in annual pensions for high deciles. When the NRA is set to 65 , the effect is highest for the first decile where it increases annual pensions by $390 €$ per year and lower for higher deciles. For the ninth decile annual pensions decrease by $233 €$.

These differences are more positive when the NRA is at 67. Again, the policy yields a positive effect on annual pensions for the lowest deciles but increasingly negative effects on annual pensions for higher deciles. While annual pensions increase for the first decile by $405 €$, they decrease by $23 €$ for the ninth decile. 
Table 10: Distributional effects in pensions, no subsidies for partial retirement

\begin{tabular}{|c|c|c|c|c|c|c|c|c|}
\hline \multicolumn{9}{|c|}{ Decile } \\
\hline & 1 & 2 & 3 & 5 & 7 & 8 & 9 & Gini coefficient \\
\hline \multicolumn{9}{|c|}{ ERA 63, NRA 65} \\
\hline No part. ret. & 10,406 & 12,077 & 13,196 & 15,188 & 17,119 & 18,107 & 19,240 & 25.46 \\
\hline Part. ret. & 10,433 & 11,927 & 12,998 & 14,869 & 16,803 & 17,764 & 18,845 & 24.88 \\
\hline Diff & 27 & -150 & -198 & -319 & -316 & -343 & -395 & -0.58 \\
\hline \multicolumn{9}{|c|}{ ERA 65, NRA 67} \\
\hline No Part. ret. & 10,290 & 11,962 & 13,014 & 14,782 & 16,562 & 17,499 & 18,666 & 24.90 \\
\hline Part. ret. & 10,423 & 11,853 & 12,836 & 14,651 & 16,430 & 17,373 & 18,587 & 24.80 \\
\hline Diff & 133 & -109 & -178 & -131 & -132 & -126 & -79 & -0.10 \\
\hline
\end{tabular}

Annual pension deciles. Based on 100,000 simulated observations. Gini coefficient if presented in percent.

Table 10 shows the distributional effects for the simulated policies without subsidies for partial retirement. The Gini coefficient reduces by 0.58 percentage points when the NRA is 65 and by 0.34 percentage points when the NRA is 67 . Thus, the result that unrestricted access to partial retirement leads to a reduction in pension inequality is robust to retirement entry age thresholds and financial subsidies for partial retirement.

Without subsidies for partial retirement, annual pensions decrease across almost all deciles with the introduction of partial retirement. With the NRA at 65, annual pensions still increase for the first decile by $27 €$ but these effects are substantially different for the ninth deciles. Here, annual pensions reduce by $395 €$. Except for the lowest income decile, these differences are markedly lower across deciles for the case with the NRA at 67 . In this case annual pensions for the lowest decile increase by $133 €$ while they decrease by $79 €$ for the ninth decile. Thus pension accrual compensations are less important to make up for losses in individual pensions due to partial retirement as the NRA increases to 67 since in this scenario individuals spend more time in partial retirement to prevent higher deductions to pensions and thus smooth consumption.

To conclude, partial retirement clearly reduces income inequality in pensions. This finding is robust to different retirement entry age thresholds as well as financial incentives for partial retirement. Not subsidizing pension accrual leads to reductions in individual pensions across almost all income deciles which could potentially push retirees with low income into social assistance. However subsidies are less needed as a compensation for pension losses when the NRA is at 67 .

\section{Conclusion}

In this paper, I develop a dynamic retirement model in order to analyze the effect of partial retirement on labor supply, public balances, and the pension income distribution. The basic model consists of an individual's annual choice to continue working 
or exit employment through one of three possible retirement paths: 1) regular retirement, 2) retirement via unemployment, or 3) retirement via partial retirement. The choice is subject to individual employment and mortality risks. Access to partial retirement is restricted. Based on the model, I investigate three different counterfactual scenarios that explore different aspects in the effect of partial retirement on employment behavior, public balances, and pension income distributions: (1) introducing partial retirement as a potential retirement path, (2) partial retirement in the context of an increased normal retirement age from 65 to 67, and (3) financial subsidies for partial retirement.

I distinguish between retirement entry (pension receipt) and employment exit behavior. I find that partial retirement reduces the average retirement age but this reduction is much smaller when the NRA is increased. It seems that people spend more time in partial retirement when the NRA is increased in order to avoid higher deductions to pensions. Especially for retirees in lower income deciles partial retirement provides a way to smooth consumption at an increased NRA.

Partial retirement yields an extension of working lives by about four to five months through a reduction of early employment exits via unemployment. However, in all cases partial retirement reduces the overall employment volume by $4.7 \%$ when the NRA is at 65 and $3.86 \%$ when the NRA is at 67 . Hence, the employment effects of partial retirement are negative, but less so at a higher NRA. Financial incentives for partial retirement yield stronger negative employment effects (a reduction by about $10 \%$ when the NRA is at 67 ) because the additional number of people who switch from full-time employment to partial retirement due to its financial incentives is higher than the amount of people who switch from unemployment to partial retirement.

Not compensating pension accrual in partial retirement leads to a decrease in pensions across almost all income deciles but these reductions are less pronounced when the NRA is 67 since more people bridge the time between ERA and NRA with partial retirement. Especially for lower income deciles partial retirement provides a way to smooth consumption when transitioning into retirement in the context of an increased NRA. In addition, subsidizing partial retirement leads to a reduction of net public balances by about $10,500(17,000) €$ per person when the NRA is $65(67)$, while this amount is far lower $(1,000$ to $3,600 €)$ when no wage or pension compensations are paid for partial retirement. The differences in fiscal consequences are mostly driven by lower reductions in SSC and IT payments, which reduce by about 13,000 to $17,000 €$ per person when partial retirement is subsidized and by about $9,500 €$ per person when partial retirement is not subsidized. Finally, I find that partial retirement reduces pension income inequality in all policy scenarios. This also holds when financial subsidies for partial retirement are removed. From this analysis it can be concluded that partial retirement is more beneficial from a public perspective when it is not subsidized because subsidies lead to more crowding out from full-time employment causing stronger negative employment effects.

Whether or not potential costs for partial retirement are worth the benefit of less inequality in pensions and of providing an additional opportunity to smooth consump- 
tion in the transition to retirement for retirees with low income remains a normative question that is subject to public discussion. The discussion should also consider the fact that partial retirement differs characteristically from policies that raise statutory age thresholds. While statutory age thresholds impose specific barriers on individual choice, allowing for partial retirement extends individual choice. There are other positive effects that might be derived from an overall introduction of partial retirement, such as an additional alternative for an individual to smooth out health shocks or potential synergetic effects when employees remain in their firms longer to potentially train new workers. These points are subject to further research. 


\section{References}

Albanese, A., B. Cockx, and Y. Thuy (2016). Working Time Reductions at the End of the Career. Do they Prolong the Time Spent in Employment? CESifo Working Paper Series 5695, CESifo Group Munich.

Atalay, K. and G. F. Barrett (2015). The Impact of Age Pension Eligibility Age on Retirement and Program Dependence: Evidence from an Australian Experiment. The Review of Economics and Statistics 97(1), 71-87.

Bellman, R. (1957). Dynamic Programming (1 ed.). Princeton, NJ, USA: Princeton University Press.

Benitez-Silva, H. (2000). A dynamic model of labor supply, consumption/saving, and annuity decisions under uncertainty. Department of economics working papers, Stony Brook University, Department of Economics.

Berg, P. B., M. K. Hamman, M. Piszczek, and C. J. Ruhm (2015). Can Policy Facilitate Partial Retirement? Evidence from Germany. IZA Discussion Papers 9266, Institute for the Study of Labor (IZA).

Blau, D. M. (2008). Retirement and consumption in a life cycle model. Journal of Labor Economics 26(1), 35-71.

Blau, D. M. and D. B. Gilleskie (2006). Health insurance and retirement of married couples. Journal of Applied Econometrics 21(7), 935-953.

Bloemen, H., S. Hochguertel, and J. Zweerink (2016). Gradual retirement in the netherlands. Research on Aging 38(2), 202-233. PMID: 25963739.

Bönke, T., G. Corneo, and H. Lüthen (2015). Lifetime Earnings Inequality in Germany. Journal of Labor Economics 33(1), 171-208.

Bonsang, E., S. Adam, and S. Perelman (2012). Does retirement affect cognitive functioning? Journal of Health Economics 31(3), 490 - 501.

Börsch-Supan, A., T. Bucher-Koenen, S. Kluth, M. Haupt, and N. Goll (2015). Vorund nachteile höherer flexibilität als instrument zur erhöhung der beschäftigung Älterer. MEA discussion papers.

Brussig, M., M. Knuth, and S. Wojtkowski (2009). Altersübergangs-report,2009-02. Technical report, Univeristät Duisburg-Essen: Institut Arbeit und Qualifikation.

Chen, Y.-P. and J. C. Scott (2006). Phased retirement: Who opts for it and toward what end. European Papers on the New Welfare 6, 16-28.

Duggan, M., P. Singleton, and J. Song (2007). Aching to retire? The rise in the full retirement age and its impact on the social security disability rolls. Journal of Public Economics 91 (7-8), 1327-1350.

Elsayed, A., A. De Grip, D. Fouarge, and R. M. Montizaan (2015). Gradual retirement, financial incentives, and labour supply of older workers: Evidence from a stated preference analysis. Netspar Discussion Paper. 
Etgeton, S. (2017). The effect of pension reforms on old-age income inequality. mimeo.

Eurofound (2016). Extending work lives through flexible retirement sscheme: Partial retirement. Eurofound: European Foundation for the Improvement of Living and Working Conditions.

Fitzenberger, B., A. Osikominu, and R. Völter (2005). Imputation Rules to Improve the Education Variable in the IAB Employment Subsample. ZEW Discussion Papers 05-10, ZEW - Zentrum für Europäische Wirtschaftsforschung / Center for European Economic Research.

French, E. (2005). The effects of health, wealth, and wages on labour supply and retirement behaviour. The Review of Economic Studies 72(2), pp. 395-427.

French, E. and J. B. Jones (2011). The effects of health insurance and self-insurance on retirement behavior. Econometrica 79(3), 693-732.

Geyer, J. and C. Welteke (2017). Closing routes to retirement: How do people respond?

Ghent, L. S., S. G. Allen, and R. L. Clark (2001). The impact of a new phased retirement option on faculty retirement decisions. Research on Aging 23(6), 671693.

Gourinchas, P.-O. and J. A. Parker (2002). Consumption Over the Life Cycle. Econometrica $70(1), 47-89$.

Graf, N., H. Hofer, and R. Winter-Ebmer (2011). Labor supply effects of a subsidized old-age part-time scheme in austria. Zeitschrift für ArbeitsmarktForschung 44(3), 217.

Gustman, A. L. and T. L. Steinmeier (2005, February). The social security early entitlement age in a structural model of retirement and wealth. Journal of Public Economics 89(2-3), 441-463.

Gustman, A. L. and T. L. Steinmeier (2008). Projecting behavioral responses to the next generation of retirement policies. Research in Labor Economics 28, 141-195.

Haan, P. and V. Prowse (2014). Longevity, life-cycle behavior and pension reform. Journal of Econometrics 178, Part 3(0), 582 - 601.

Haan, P. and V. L. Prowse (2015, April). Optimal Social Assistance and Unemployment Insurance in a Life-Cycle Model of Family Labor Supply and Savings. IZA Discussion Papers 8980, Institute for the Study of Labor (IZA).

Heyma, A. (2004). A structural dynamic analysis of retirement behaviour in the netherlands. Journal of Applied Econometrics 19(6), 739-759.

Hochfellner, D., D. Müller, and A. Wurdack (2012). Biographical data of social insurance agencies in germany: Improving the content of administrative data. Schmollers Jahrbuch : Zeitschrift für Wirtschafts- und Sozialwissenschaften 132(3), 443-451. 
Huber, M., M. Lechner, and C. Wunsch (2016). The effect of firms' phased retirement policies on the labor market outcomes of their employees. ILR Review 69(5), 12161248 .

Inderbitzin, L., S. Staubli, and J. Zweimüller (2016). Extended Unemployment Benefits and Early Retirement: Program Complementarity and Program Substitution. American Economic Journal: Economic Policy 8(1), 253-88.

Karlstrom, A., M. Palme, and I. Svensson (2004). A dynamic programming approach to model the retirement behaviour of blue-collar workers in sweden. Journal of Applied Econometrics 19(6), 795-807.

Li, X. and N. Maestas (2008). Does the rise in the full retirement age encourage disability benefits applications? evidence from the health and retirement study. Working papers, University of Michigan, Michigan Retirement Research Center.

Machado, C. S. and M. Portela (2012). Hours of work and retirement behavior. IZA Discussion Papers 6270, Institute for the Study of Labor (IZA).

Maestas, N. and J. Zissimopoulos (2010). How longer work lives ease the crunch of population aging. Journal of Economic Perspectives 24(1), 139-60.

Manoli, D., K. Mullen, and M. Wagner (2014). Policy Variation, Labor Supply Elasticities, and a Structural Model of Retirement. IZA Discussion Papers 8659, Institute for the Study of Labor (IZA).

Merkurieva, I. (2016). Late Career Job Loss and the Decision to Retire. Discussion Paper Series, Department of Economics 201606, Department of Economics, University of St. Andrews.

Moffitt, R. (1983). An economic model of welfare stigma. The American Economic Review 73 (5), 1023-1035.

Munzenmaier, F. and J. Paciero (2002). Replacement ratios and phased retirement -a new tune on an old fiddle. Benefits 18(1).

Rohwedder, S. and R. J. Willis (2010). Mental Retirement. Journal of Economic Perspectives 24(1), 119-38.

Rust, J. (1987). Optimal replacement of gmc bus engines: An empirical model of harold zurcher. Econometrica 55(5), 999-1033.

Rust, J. (1989). A dynamic programming model of retirement behavior. In The Economics of Aging, NBER Chapters, pp. 359-404. National Bureau of Economic Research, Inc.

Rust, J. (1994). Structural estimation of markov decision processes. Handbook of econometrics $4(4)$.

Rust, J. and C. Phelan (1997). How social security and medicare affect retirement behavior in a world of incomplete markets. Econometrica 65(4), pp. 781-831. 
Staubli, S. (2011). The impact of stricter criteria for disability insurance on labor force participation. Journal of Public Economics 95(9-10), 1223-1235.

Staubli, S. and J. Zweimüller (2013). Does raising the early retirement age increase employment of older workers? Journal of Public Economics 108, 17 - 32.

Stock, J. H. and D. A. Wise (1990). Pensions, the Option Value of Work, and Retirement. Econometrica 58(5), 1151-80.

Van der Klaauw, W. and K. I. Wolpin (2008). Social security and the retirement and savings behavior of low-income households. Journal of Econometrics 145(1), $21-42$.

Van Soest, A., A. Kapteyn, and J. M. Zissimopoulos (2007). Using stated preferences data to analyze preferences for full and partial retirement.

Wadensjö, E. (2006). Part-Time Pensions and Part-Time Work in Sweden. IZA Discussion Papers 2273, Institute for the Study of Labor (IZA).

Wagner, G. G., J. R. Frick, and J. Schupp (2007). The german socio-economic panel study (soep)-evolution, scope and enhancements.

Wanger, S. (2009). Altersteilzeit- beliebt, aber nicht zukunftsgerecht. iab kurzbericht, 8-2009, 1-12. Technical report, Nuremberg. 


\section{Appendix}

\section{A Institutional background}

The German Statutory Pension Insurance, is a pay-as-you-go funded system. It covers the majority of the working population and is the main source of income after retirement entry. The Pension Fund is mainly financed by contributions through a payroll tax, evenly split between employee and employer.

\section{A.1 The Altersteilzeit policy}

In 1996, Germany introduced the Altersteilzeit (ATZ) policy with the aim to provide elderly employees with the option to gradually transition from work to retirement. ${ }^{18}$ It was also intended to extend working lives by offering an alternative to abrupt early retirement. This policy sets legal standards for requirements as well as compensation and pension contributions for gradual retirement options in firms. More precisely, every employee aged 55 or older who has worked at least 1080 days in the past five years can reduce their work hours by $50 \%$. Furthermore, employees in ATZ have to be paid at least $50 \%$ of their previous full-time wages. Employers are not legally required to provide ATZ such that further standards were set in agreements within firms or collective wage agreements (Brussig et al., 2009). Among ATZ providing firms, these agreements contained compensation floors of at least $20 \%$ of previous wages and $40 \%$ of previous pension points. The average compensation for wages among ATZ firms was 23\% (Wanger, 2009) while pension point compensations ranged from 30-45\% (Berg et al., 2015).

There are two options to realize the reduction in working time: The employee can either work part-time for the entire ATZ-period or opt for the so-called block model that consists of full-time work in the first half of the ATZ period and a leave of absence in the second half. With a take-up rate of $88 \%$ in 2007 (Wanger, 2009), the block model is the more popular variant among ATZ-takers. While ATZ could be extended over a period of ten years, Figure 7 shows that virtually noone remains in ATZ for more than six years since this was the maximum number of years, the FEA would pay supplements to employers. These FEA subsidies stopped in 2009, while the minimum standards remained. Note that for the studied cohorts, workers in ATZ and unemployed can enter full retirement up to three years earlier than regular retirees.

Figure 8 shows that ATZ-take-up rose steadily since its introduction in 1996. From 2004 onwards ATZ-take-up reached about $18 \%$ of all employees subject to social security contributions aged 55 to 64 (Wanger, 2009), making it a relevant pathway into retirement.

We can also see that ATZ was significantly more relevant to West Germans. In addition, East Germans exhibited different employment effects than West Germans with the introduction of ATZ which could be contributed to differences in the respective economies (Huber et al., 2016). The extraordinary peek in ATZ-take-up in 2009 further indicates that employment effects due to ATZ are different in economic busts (Huber et al., 2016). 2009 marks the year of the European Economic Crisis. However, the periods in the present sample only extend to 2007. Although the share of women in ATZ seems non-negligible, it only rose when eligibility was extended to part-time employees (Brussig et al., 2009), making it an economically less relevant group of ATZ employees.

\footnotetext{
${ }^{18}$ The law governing ATZ (Altersteilzeitgesetz): https : //www.gesetze - im internet.de/bundesrecht/alttzg $g_{1} 996 /$ gesamt.pdf
} 
Figure 7: Distribution of time spent in ATZ

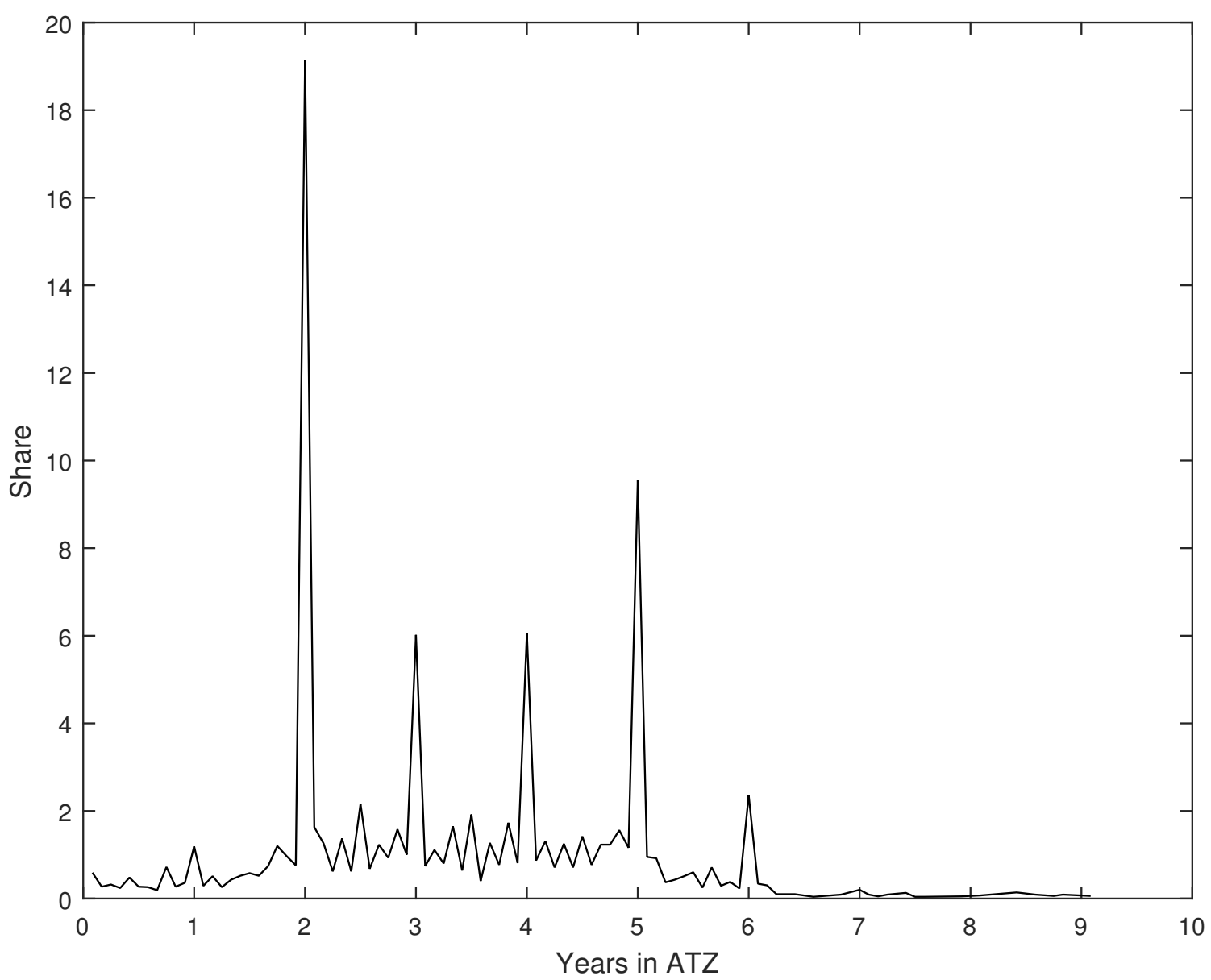

Source: Own calculations based on BASiD. Based on 258,296 monthly observations. Sample restrictions: Only validated accounts, all German men, no disability insurance receipt, at least five pension contribution years, at least two years tenure at age 54 . 
Figure 8: Share of ATZ employees among all employees

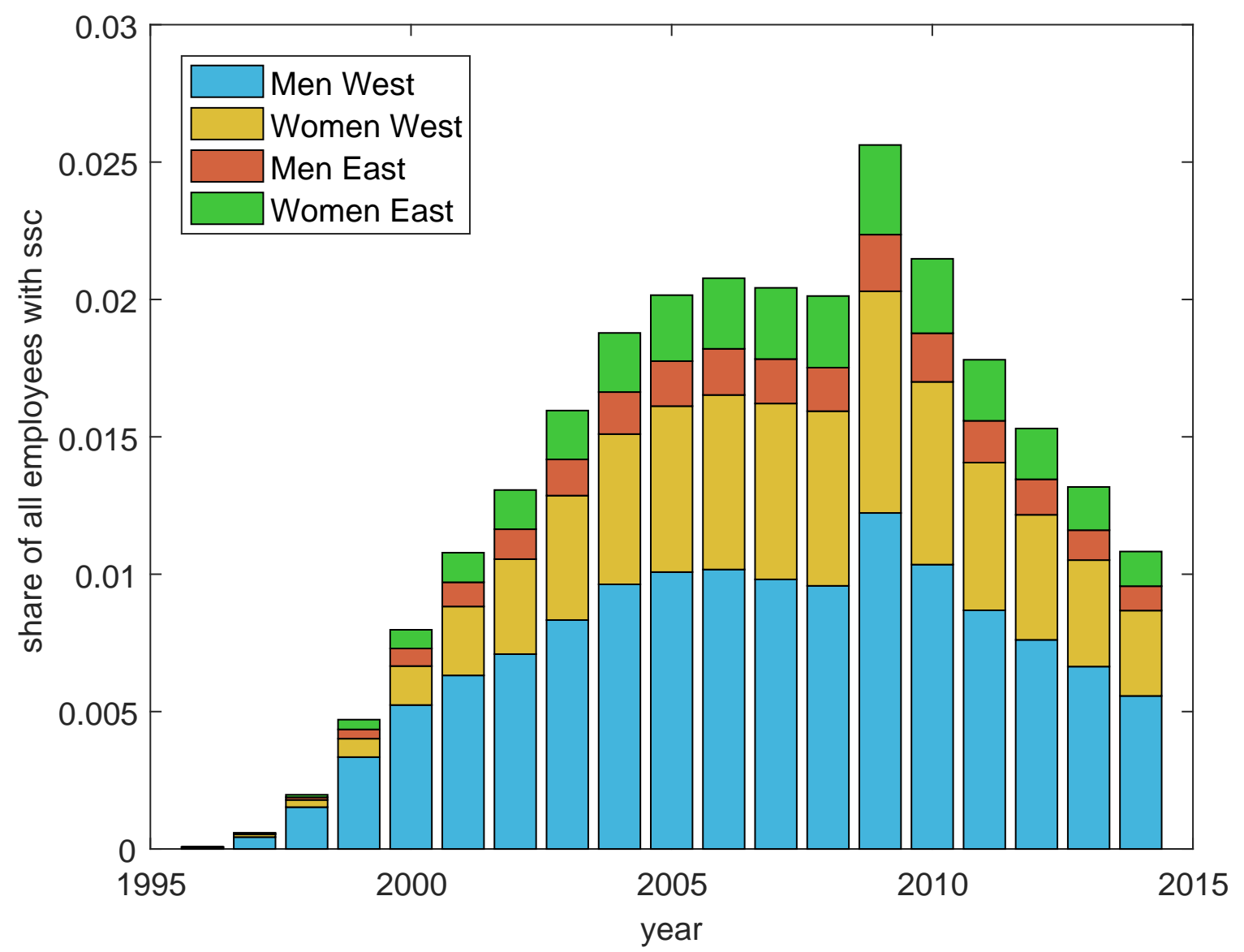

Source: Own calculations based on Deutsche Rentenversicherung 2011, 2016

\section{A.2 Retirement after unemployment}

Besides the presented retirement paths, workers from the studied cohorts have the additional option to retire at the early retirement age of 60 if they spent at least 12 months in UI receipt after turning 58.5. Depending on their previous employment history, workers are eligible to 18-32 months of unemployment insurance and they can use these months to bridge the time between labor market exit and official retirement entry three years prior to the normal old-age early retirement age of 63 . This means that individuals that retire via unemployment are factually retired from the point they enter unemployment.

Retirees after ATZ have the same early retirement options and face the same pension deductions for early retirement (see Table 11). Periods spent in UI yield about $80 \%$ of the contributions from previous full-time employment. That is, relative to full-time employment, pension contribution replacements are higher in ATZ than in unemployment. Moreover, the replacement rate of labor earnings is lower in UI than in ATZ. To sum up the differences between these two retirement paths: Retirement via ATZ has higher financial incentives and ATZ employees have to work $50 \%$ of the bridge period while the unemployed have fully stopped working. Thus, when studying partial retirement-take-up through ATZ-take-up, retirement via unemployment should be considered as a voluntary alternative retirement option. 


\section{B Auxiliary tables}

Table 11: Retirement access factors by cohorts and retirement type

\begin{tabular}{ccccccc}
\hline & \multicolumn{4}{c}{ ATZ/Unemployment } & Regular Retirement \\
\hline age & $\mathbf{1 9 4 0}$ & $\mathbf{1 9 4 1}$ & $\mathbf{1 9 4 2 - 1 9 4 5}$ & $\mathbf{1 9 4 6}$ & $\mathbf{1 9 4 7}$ & $\mathbf{1 9 4 0 - 1 9 4 7}$ \\
\hline 60 & 0.892 & 0.856 & 0.820 & 0.000 & 0.000 & 0.000 \\
61 & 0.928 & 0.892 & 0.856 & 0.856 & 0.000 & 0.000 \\
62 & 0.964 & 0.928 & 0.892 & 0.892 & 0.892 & 0.000 \\
63 & 1.000 & 0.964 & 0.928 & 0.928 & 0.928 & 0.928 \\
64 & 1.000 & 1.000 & 0.964 & 0.964 & 0.964 & 0.964 \\
65 & 1.000 & 1.000 & 1.000 & 1.000 & 1.000 & 1.000 \\
66 & 1.060 & 1.060 & 1.060 & 1.060 & 1.060 & 1.060 \\
67 & 1.120 & 1.120 & 1.120 & 1.120 & 1.120 & 1.120 \\
\hline
\end{tabular}

Retirement access factors for retirement after ATZ/unemployment and regular retirement. Access factors of 0.000 indicate that access is not possible for that cohorttype combination Retirement entry for cohort 1946 can only be observed, if occurrence is at age 61 . Retirement entry for cohort 1947 is outside the observed sample.

Own Illustration 


\section{Imputation of top-coded earnings}

Since wage information in German administrative dataset are right-censored, earnings reported as equal to the annual-specific contribution ceiling $z_{t}$ are imputed. The imputation of top coded earnings is based on the assumption that earnings $w_{i}^{f}$ exceeding a minimum earnings threshold $\tilde{w}$ are distributed according to the Pareto law. Then, the probability to observe an income $w_{i}^{f} \geq \tilde{w}$ is given by

$$
1-F\left(w_{i}\right)=\left(\frac{\tilde{w}}{w_{i}}\right)^{\alpha}
$$

where $F\left(w_{i}\right)$ denotes the cumulative distribution function (cdf) on the interval $[\tilde{w}$,inf] and $\alpha$ is the pareto-coefficient that will be estimated for the imputation. Moreover, let $n$ be the number of earners with $w_{i}^{f} \geq \tilde{w}$. In addition, earners with observed wages are ranked in ascending order of their income and accordingly assigned a rank $r_{i}$. Zipf's law establishes a relation between the rank $r_{i}$ and the cdf according to

$$
\frac{r_{i}}{n} \cong\left(\frac{\tilde{w}}{w_{i}}\right)^{\alpha}
$$

Taking the logarithm yields

$$
\ln \left(\frac{r_{i}}{n}\right)=-\alpha \quad \ln \left(\frac{w_{i}}{\tilde{w}}\right)
$$

This equation enables the estimation of the pareto-coefficient $\alpha$ by OLS. After this, missing earnings $w_{i} \geq z_{t}$ are imputed by putting random draws into the inverse cdf. Since $z_{t}$ is annual-specific, the estimation of $\alpha$ and the subsequent imputation is performed for each year separately. For each imputation, I set $\tilde{w}$ equal to the $90^{t h}$ percentile of all observations below the respective contribution ceiling. Thus, I assume that at least $10 \%$ of the top earnings on the interval $\left[0, z_{t}\right]$ follow a Pareto distribution.

Figure 9 shows the coarsened distribution of daily wages before and after the imputation. It can be seen that the imputation works well to smooth out the mass points at the wageceiling. 
Figure 9: Distribution of daily wages before and after imputation of top-coded earnings

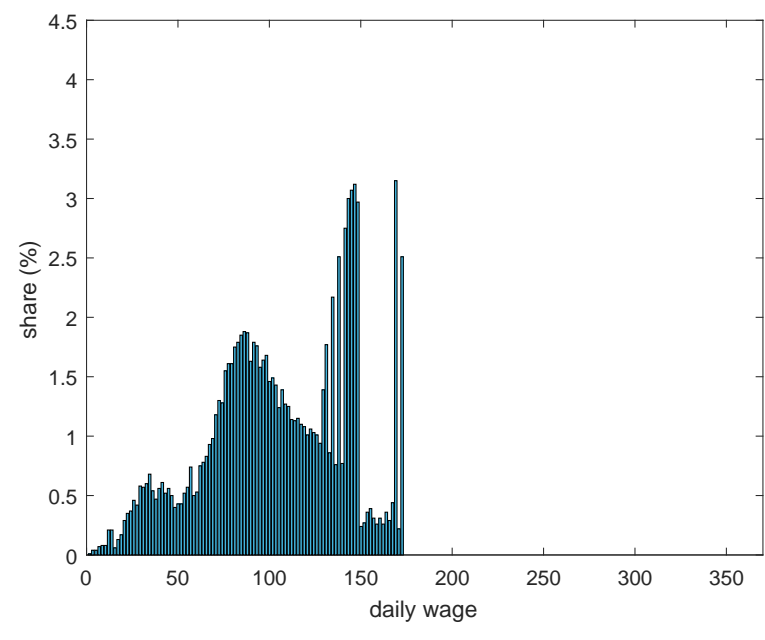

(a) Pre imputation

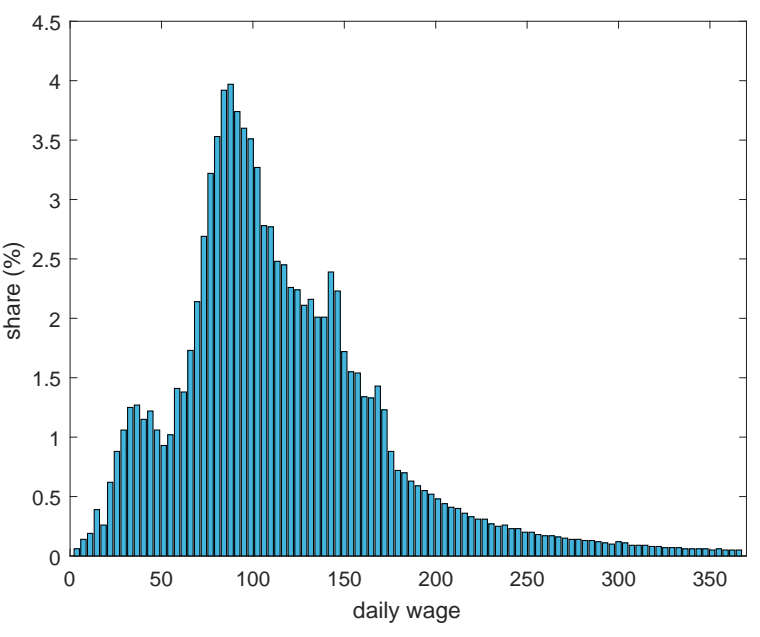

(b) Post imputation

Source: Own calculations based on BASiD. Due to confidentiality law, the distribution is coarsened to a minimum of 20 observations per $\mathrm{X}$ value and wages in the 99th percentile are cut off in the plot with imputed earnings. Differences between the figures in the distribution below the wage ceiling occur due to the coarsening. The true distribution does not have differences between right-censored and imputed wages in the distribution below the wage ceiling. 


\section{Further results}

Figure 10: Policy Simulation: Normal retirement age set to 67, no early retirement for retirement after unemployment/partial retirement

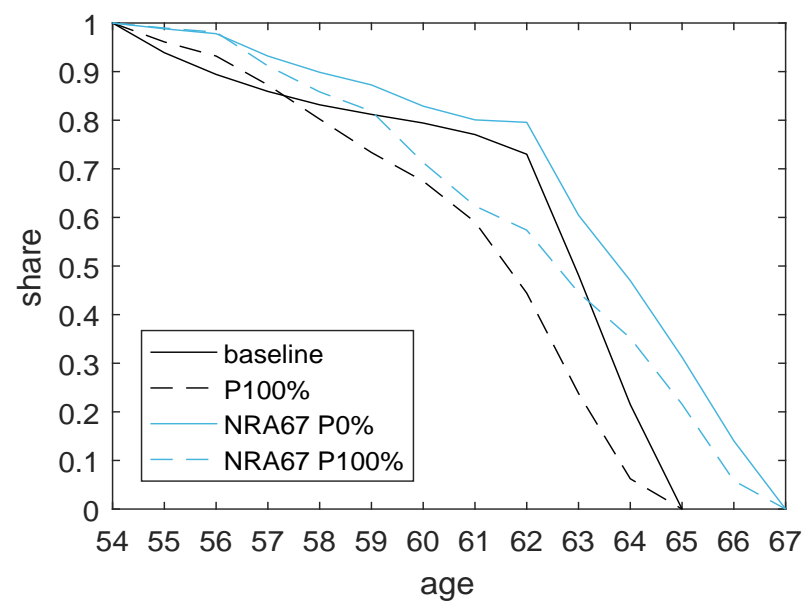

(a) Full-time

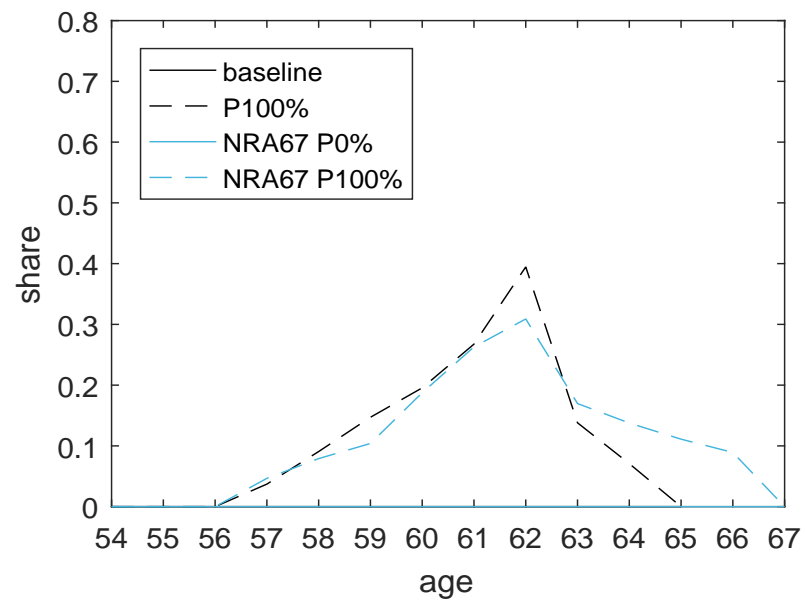

(c) Partial retirement

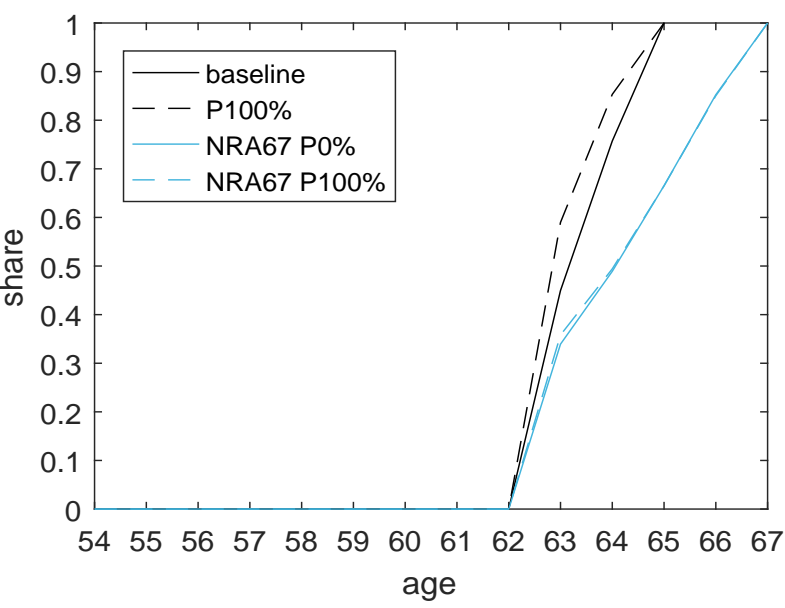

(b) Retirement

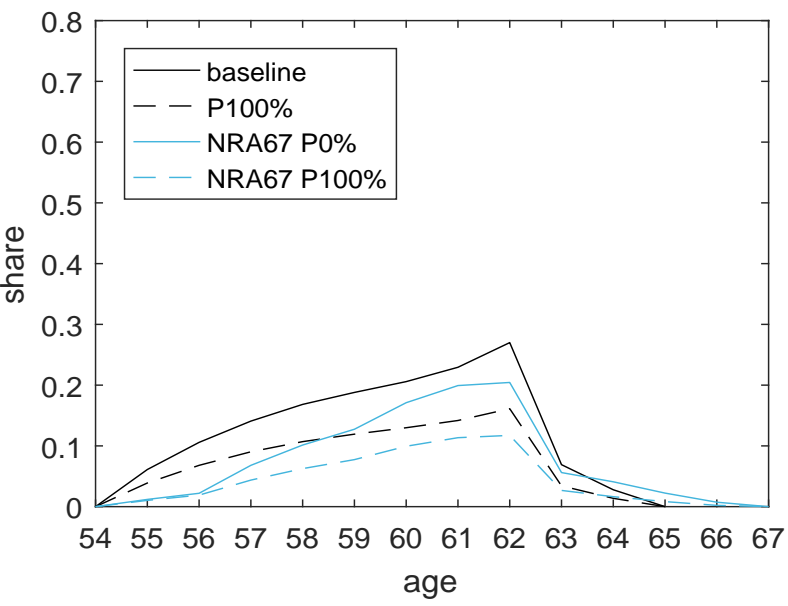

(d) Unemployment

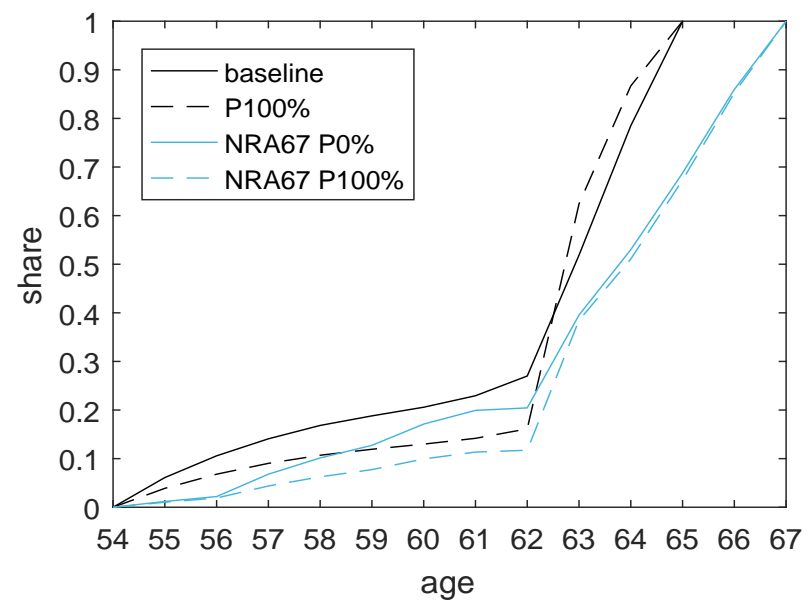

(e) Non-employment

Source: Own calculations based on BASiD. Based on 100,000 simulated observations. Figure depicts shares in each employment state by age. Sample is conditioned to $100 \%$ full-time employment at age 54 and $100 \%$ retirement at age 67 